Research Article

\title{
Cyclic Testing of Concrete-Filled Double-Skin Steel Tubular Column to Steel Beam Joint with RC Slab
}

\author{
Dongfang Zhang $\left(D^{1}{ }^{1}\right.$ Junhai Zhao, ${ }^{1}$ and Shuanhai $\mathrm{He}^{2}$ \\ ${ }^{1}$ School of Civil Engineering, Chang'an University, Xi'an, Shaanxi 710061, China \\ ${ }^{2}$ Highway School, Chang'an University, Xi'an, Shaanxi 710064, China \\ Correspondence should be addressed to Dongfang Zhang; zhangdongfang_2008@163.com
}

Received 11 March 2018; Accepted 24 June 2018; Published 26 July 2018

Academic Editor: Ahmed Mebarki

Copyright (c) 2018 Dongfang Zhang et al. This is an open access article distributed under the Creative Commons Attribution License, which permits unrestricted use, distribution, and reproduction in any medium, provided the original work is properly cited.

\begin{abstract}
The design of composite joints for connecting concrete-filled double-skin tubular (CFDST) columns to steel beams supporting reinforced concrete (RC) slabs is presented in this paper. Five half-scale specimens were designed, including four composite joints with RC slab and one bare steel beam joint, and were tested under a constant axially compressive force and lateral cyclic loading at the top end of the column to evaluate their seismic behavior. The main experimental parameters were the construction of the joint and the type of the column. The seismic behaviors, including the failure modes, hysteresis curves, ductility, strength and stiffness degradation, and energy dissipation, were investigated. The failure modes of the composite joints depended on the joint construction and on the stiffness ratio of beams to columns. Joints of stiffening type had significantly higher load-bearing and deformation capacities than joints of nonstiffening type. Compared with the bare steel beam joint, the bearing capacities of the composite joints with RC slabs were markedly increased. The composite action was remarkable under sagging moments, resulting in larger deformation on the bottom flanges of the beams. Overall, most specimens exhibited full hysteresis loops, and the equivalent viscous damping coefficients were $0.282 \sim 0.311$. The interstory drift ratios satisfied the requirements specified by technical regulations. Composite connections of this type exhibit excellent ductility and favorable energy dissipation and can be effectively utilized in superhigh-rise buildings erected in earthquake zones.
\end{abstract}

\section{Introduction}

A CFDST column is composed of an outer tube and an inner tube that is fully or partly filled with concrete. The mechanical behaviors of CFDST columns have been studied by many researchers in recent years. The results indicate that CFDST columns exhibit higher bearing capacities, ductility, and energy consumption with smaller sections compared with traditional concrete-filled steel tubular (CFST) columns, increasing space utilization in buildings $[1,2]$. When used in buildings, CFDST columns are usually connected to steel beams. However, there have been few studies on such connections, which tend to be complex owing to the double-skin tubes. As well as, there are no standard codes and practices that can be applied, which have hampered the application of CFDST columns in high-rise buildings in seismic regions.
To accelerate the application of CFDST columns, a new type of joint of the CFDST column to steel beam was proposed by Zhang et al. [3-5]. The experimental study on the new type of joint was investigated. The results indicate that the joint has the high bearing capacity, excellent ductility, and favorable energy dissipation. And beam failure modes of the joints were realized by modifying the construction details to satisfy the design principles of "strong column, weak beam" and "strong joint, weak component" for seismic resistance. Huang [6] investigated the seismic behavior of CFST built-up columns by experimental tests and finite element method analyses. The results indicated that CFST built-up columns had a favorable seismic performance and can be used in the practical bridge engineering.

In a real structural system, CFDST columns are generally attached to steel beams, which are, in turn, connected to 


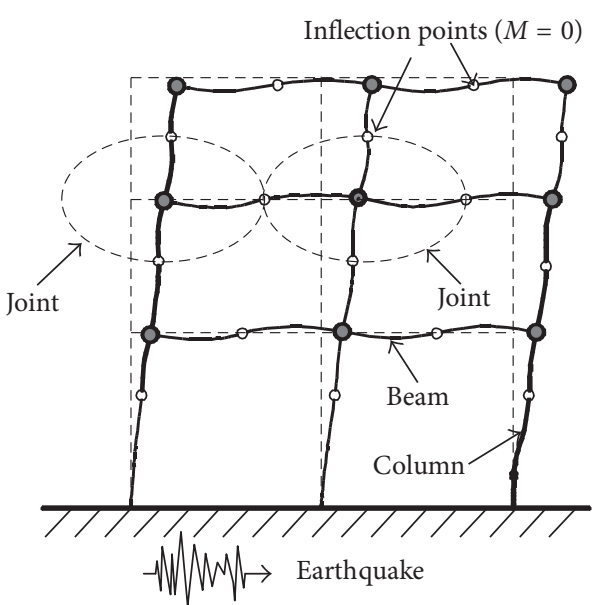

(a)

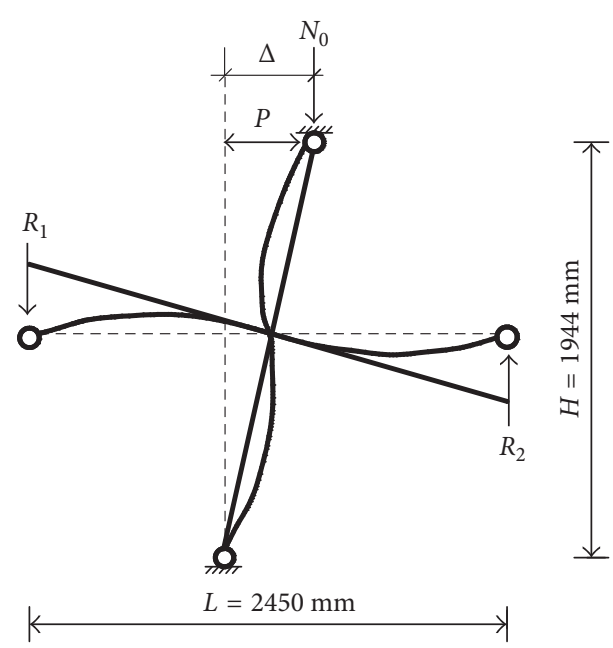

(b)

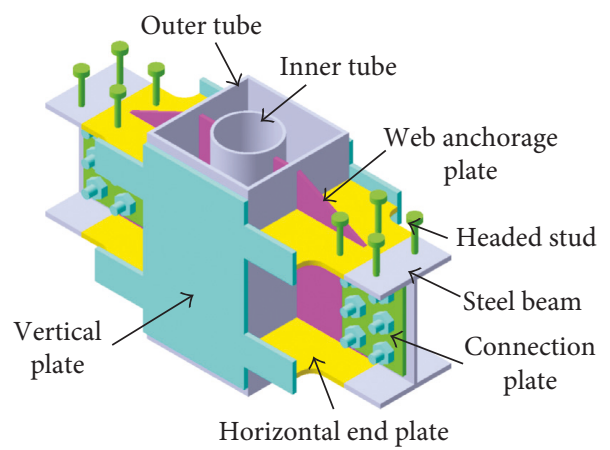

(c)

FIgURE 1: Schematic views of the joint model. (a) Frame. (b) Joint model. (c) Construction of the composite joint specimen.

reinforced concrete (RC) slabs by shear stubs. These two components generally exhibit cooperative behavior that enhances the bearing capacity and continuity of the overall rigid frame system. Kim et al. [7] conducted experiments on five full-scale connections considering slab effects under cyclic loads. The results showed that the strains on the bottom flanges of the beams were so large that the bottom flanges exhibited severe fracturing. Cheng et al. [8] investigated the seismic performance of four steel-beam-toCFST-column joints considering the effects of floor slabs. The results indicated that the composite action of floor slabs and steel beams is significant under positive bending and minimal under negative bending. Liao et al. [9] studied the effects of RC slabs on the seismic behavior of composite joints with concrete-encased CFST columns under cyclic loading. The results revealed that the presence of an RC slab could significantly enhance the beam strength and thus shift the joint failure mode from beam failure to joint and column failure. Han and $\mathrm{Li}[10]$ analyzed the seismic performance of joints connecting CFST columns to steel beams with RC slabs through experiments. In the tests, both beam failures and column failures were observed. The presence of an RC slab can notably increase both the stiffness and strength of a joint under a positive moment, and thus, the failure mode may shift from beam failure to column failure. Upon reviewing the above literature, it can be found that slab effects are very important to the seismic behavior of beamcolumn connections and should be accounted for in structural designs. However, designs for the connection of CFDST columns to steel beams that consider RC slab effects are very rare worldwide.

In this study, four joint specimens with RC slabs and a bare steel beam joint specimen were designed and tested under cyclic loads at the top end of the column. The specific purpose of the study was to investigate the composite effects on seismic performance, including the failure modes, hysteresis curves, bearing capacity, ductility, energy dissipation, and strength and stiffness degradation, due to the presence of an RC slab. Some useful conclusions and suggestions are proposed for the seismic design of steel-beam-to-CFDST-column joints based on the results, which have significance for the application of CFDST columns in composite structures.

\section{Experimental Program}

2.1. Design of the Test Specimens. To investigate the effects of a concrete slab on the seismic behavior of the newly proposed type of joint for connecting CFDST columns to steel beams, five half-scale cruciform joint specimens were designed in accordance with the inflection points of the beams and columns of a moment-resisting frame (as shown in Figure 1(a)) and were then tested under low-reversal 
TABLE 1: Details of the test specimens.

\begin{tabular}{lcccc}
\hline Specimen & Infilled concrete & Web anchorage plates & Thickness of the RC slab (mm) & Reinforcements \\
\hline SBJ1 & C30 & Stiffening & NA & NA \\
CBJ1 & C30 & Nonstiffening (VAR) & 100 & 10 mm@100 \\
CBJ2 & NA (VAR) & Stiffening & 120 (VAR) & $10 \mathrm{mm@100}$ \\
CBJ3 & C30 & Stiffening & 100 & $10 \mathrm{mm@100}$ \\
CBJ4 & C30 & Stiffening & $10 \mathrm{~mm} 100$ \\
\hline
\end{tabular}

Note.10 mm@100 denotes reinforcements of $10 \mathrm{~mm}$ in diameter and $100 \mathrm{~mm}$ in spacing; C30 is the grade of the concrete in the Chinese standard; CBJ denotes a composite beam joint; SBJ denotes a bare steel beam joint.

cyclic loading. The whole sizes of the joint model were shown in Figure 1(b). To achieve an excellent behavior of the CFDST column, a web anchorage plate was attached to the inner steel tube for connection to the steel beam through the outer steel tube, as shown in Figure 1(c). A horizontal end plate with a reduced section was also welded to the outer tube wall and the web anchorage plate, for welding to the flange of the steel beam. And then, a vertical plate was welded around the connection region to strengthen the stability of the composite joint. Finally, the RC slab was connected to the flange of each steel beam by two rows of headed studs. And the concrete that filled the steel tubes were poured together with the RC slabs.

The parameters of these specimens, which included four joints with beams supporting RC slabs (CBJ1 CBJ4) and one joint with bare steel beams (SBJ1) for comparison, can be seen in Table 1. Specimen CBJ4 was used as the benchmark for comparison with the other composite joint specimens, which was a composite joint with an RC slab of $100 \mathrm{~mm}$ in thickness, web anchorage plates of the stiffening type, and concrete fully filled into the steel tubes. Specimen SBJ1 was a bare steel beam joint. Specimen CBJ1 was a composite joint with an RC slab, but web anchorage plates of the nonstiffening type. Specimen CBJ2 was also a composite joint with an RC slab, but the inner circular tube of the column was not filled in with concrete. Specimen CBJ3 was a composite joint with an RC slab of $120 \mathrm{~mm}$ in thickness. The detailed construction information for the test specimens and the RC slabs is illustrated in Figures 2 and 3. The RC slabs were $900 \mathrm{~mm}$ in width and either $100 \mathrm{~mm}$ or $120 \mathrm{~mm}$ in thickness. Two layers of reinforcements of $10 \mathrm{~mm}$ in diameter and $100 \mathrm{~mm}$ in spacing were placed in two crossing directions. These reinforcements were designed to be of HRB400 grade based on the Chinese standard. The section of each column consisted of an outer square tube and an inner circular tube of seamless steel filled in with concrete. The dimensions of these tubes were $250 \times 250 \times 8$ (side length $\times$ side length $\times$ thickness, unit: $\mathrm{mm}$ ) for the square section and $133 \times 6$ (diameter $\times$ thickness, unit: $\mathrm{mm}$ ) for the circular section. The dimensions of the $\mathrm{H}$-shaped section of each steel beam were $244 \times 175 \times 7 \times 11$ (height $\times$ flange width $\times$ web thickness $\times$ flange thickness, unit: $\mathrm{mm}$ ). The detailed dimensions of the web anchorage plates and vertical plate are shown in Figure 4.

2.2. Material Properties. The strength and elastic modulus of the steel were measured in accordance with the GB/T 228.12010 standard [11]. The web anchorage plates and the tubes were constructed using the same type of steel, whereas the horizontal end plates and the vertical plates were constructed using another type of steel. The detailed mechanical properties of all steel components are presented in Table 2. The strength of the concrete was modulated by iterating on the mixture ratio, and ultimately, a cement: sand: gravel: water: admixture ratio of $1: 1.46: 2.71: 0.48$ : 0.20 was chosen. In total, 18 concrete cubes with side lengths of $100 \mathrm{~mm}$ were poured and tested to measure their compressive strength, and the average strength value was $f_{\text {cu }}=32.84 \mathrm{MPa}$.

2.3. Cyclic Testing Apparatus. This experimental study aimed at evaluating the seismic behavior of the tested joints under seismic action, and the pseudostatic test method was adopted in this study in accordance with the Chinese standard JGJ/T 101-2015 [12]. The test setup was fabricated to reproduce the boundary conditions of a cruciform joint model (as shown in Figure 1(a)) of a moment-resisting frame, as shown in Figure 5. A top of the vertical hydraulic jack was glidingly attached to the reaction frame, and a spherical hinge was placed between the actuator and the column in an attempt to simulate the inflection point of a joint specimen. The bottom of the column was placed on a hinged support rigidly bolted to the foundation beam. Two rigid links with load cells were established at the free ends of both the left and right beams; one side of each rigid link was hinged at the beam end, and the other side was pinned to a strong support rigidly bolted to the foundation beam. A horizontal hydraulic jack was rigidly bolted to the reaction wall for the application of a lateral low-reversal loading at the top end of the column with a maximum actuator stroke of $\pm 100 \mathrm{~mm}$ to consider the $P$ - $\Delta$ effect in a real structural system. The vertical hydraulic jack rated for $2000 \mathrm{kN}$ was placed at the top of the column to simulate the effect of the upper floors in a multistory building. To avoid torsion of the specimens during the loading process, an out-of-plane restraining brace was placed on each side of the beams, as shown as in Figure 5(b).

2.4. Loading Procedure. For the testing of all specimens, a constant axial load of $1500 \mathrm{kN}$ was first applied by the vertical hydraulic jack at the top of the column once all instrumentation had been calibrated. A horizontal lowreversal loading was then applied under displacement control, as depicted in Figure 6; the loading profile was based on the recommendations from the Chinese standard JGJ/T 101-2015 [12]. For convenience in describing the testing process, pushing and pulling actions of the horizontal 


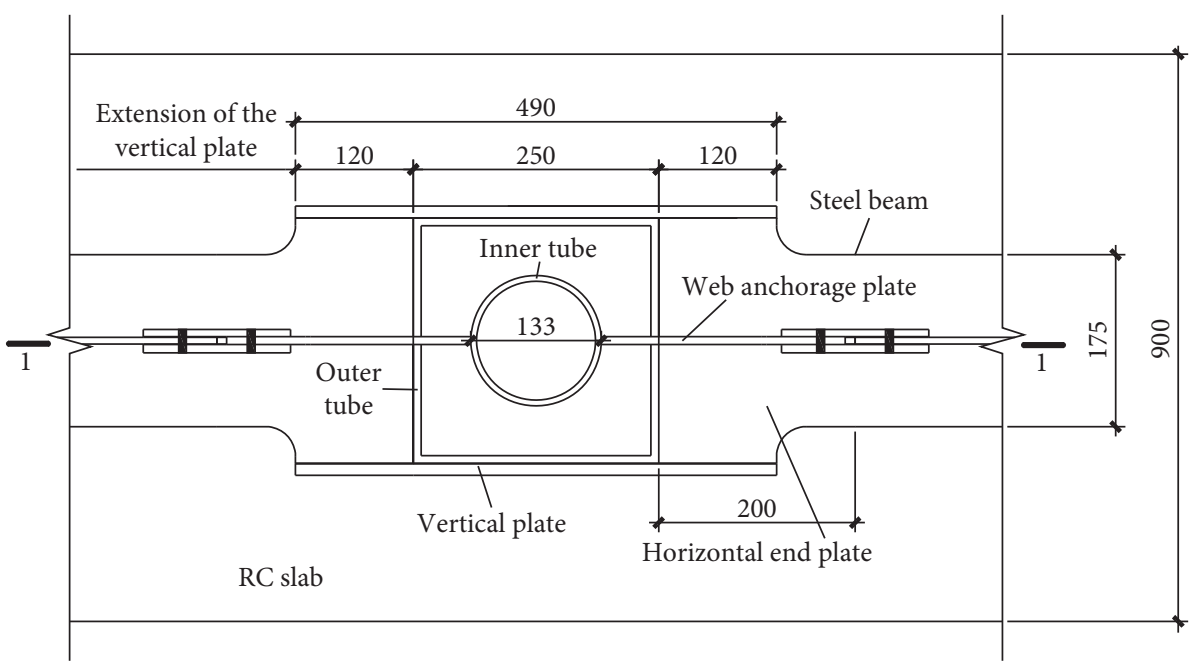

(a)

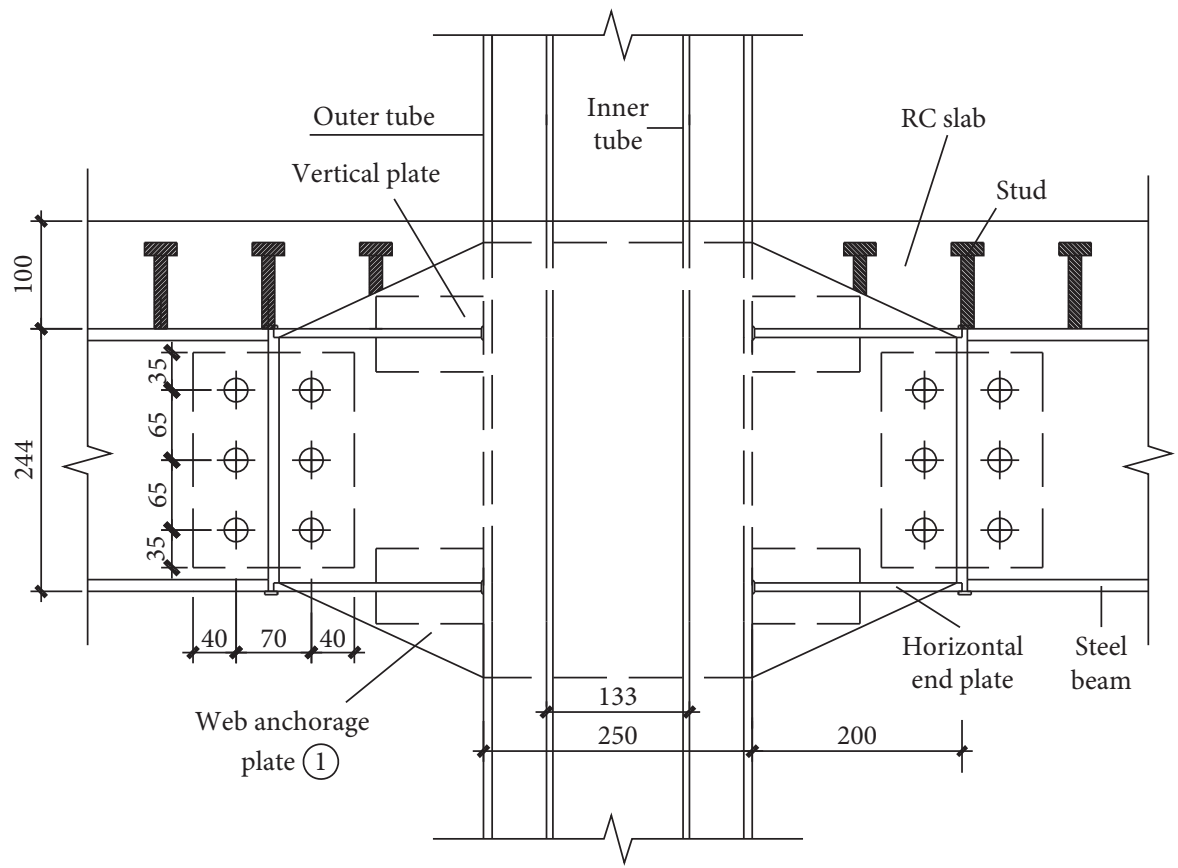

(b)

Figure 2: Details of the composite joint CBJ4: (a) plan view; (b) cutaway view of 1-1.

actuator are defined as corresponding to positive $(+)$ and negative $(-)$ values, respectively. The loading process began with one cycle each of lateral displacements of $\pm 6, \pm 12$, and \pm 18 . Subsequently, sets of three cycles with progressively increasing lateral displacement amplitudes of $\pm 24, \pm 30, \pm 36$, $\pm 42 \ldots$ were performed until failure or until the load fell below $85 \%$.

2.5. Layout of Instruments. The lateral drift and load at the end of columns $(P-\Delta)$ were automatically recorded by transducers inside the MTS hydraulic actuator. Furthermore, thirteen linear variable differential transformers (LVDTs) were mounted on the specimens to measure the joint rotation, shear deformation of the panel zone, sliding displacement of the slab, and lateral displacement of the beam and the column. The arrangement of the LVDTs is depicted in Figure 7. Strain gauges were placed on the steel beam to obtain the strain distributions nearby the column, as shown in Figure 8.

\section{Results and Discussion}

\subsection{Failure Modes}

3.1.1. Specimen SBJ1. Test specimen SBJ1 was the bare steel beam joint, with web anchorage plates of the stiffening type, and the failure modes are shown in Figure 9. Complete cracking of the weld at the bottom flange of the left beam occurred (as shown in Figure 9(a)), and the base metal of the 


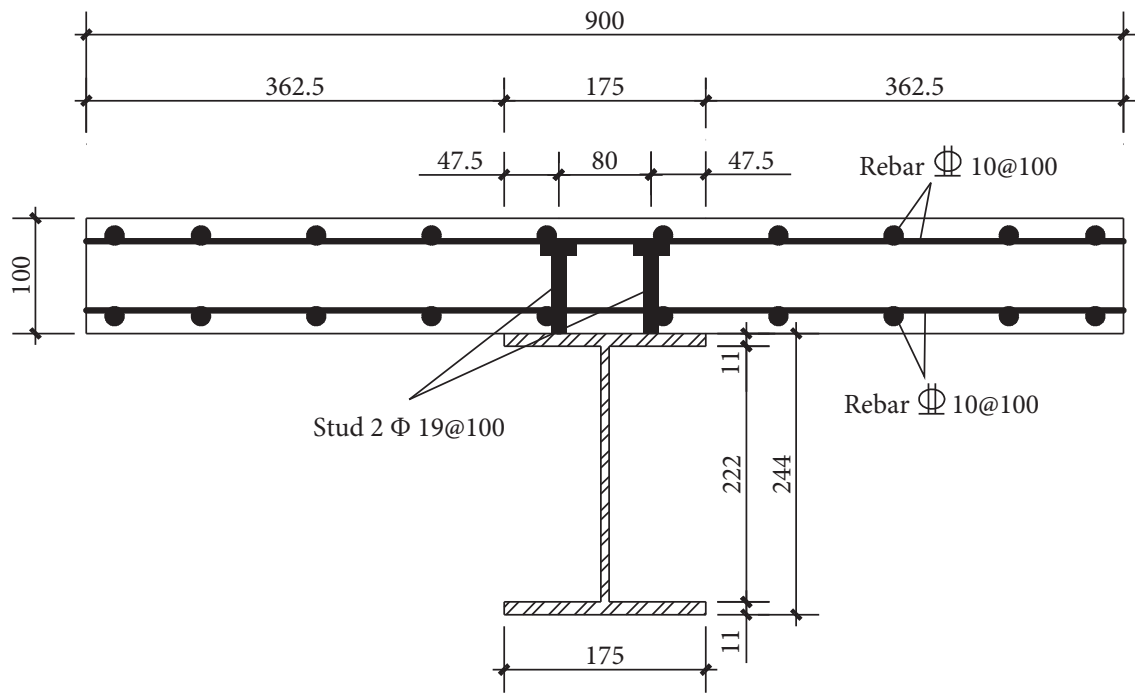

Figure 3: Section of the composite beam.
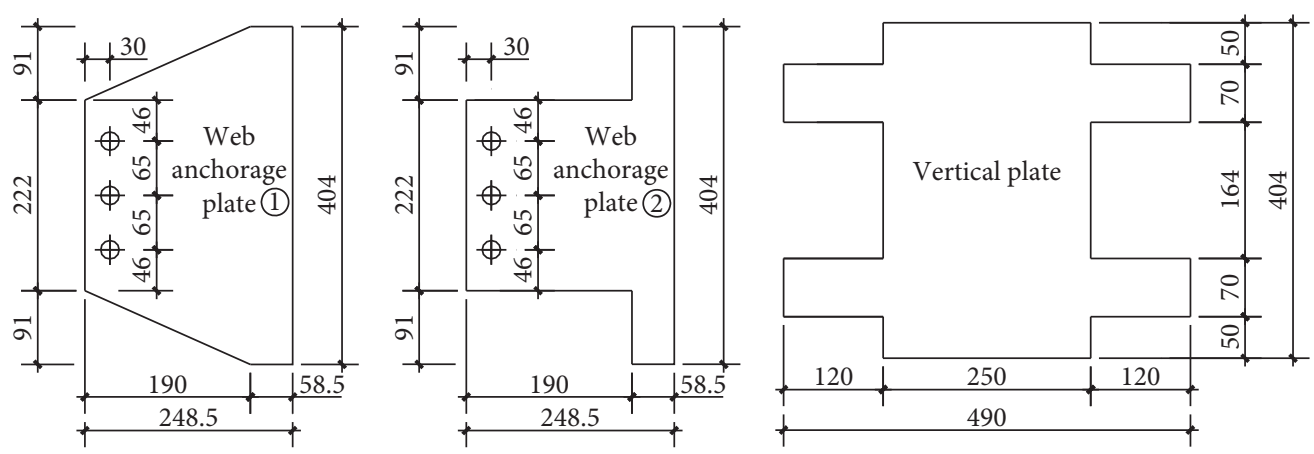

Figure 4: Details of the web anchorage plates and vertical plate.

TABle 2: Material properties of the steel components.

\begin{tabular}{lcccc}
\hline Items & Thickness $t(\mathrm{~mm})$ & Yield strength $f_{\mathrm{y}}(\mathrm{MPa})$ & Tensile strength $f_{\mathrm{u}}(\mathrm{MPa})$ & Elastic modulus $E_{\mathrm{s}}\left(10^{5} \mathrm{MPa}\right)$ \\
\hline Square tube & 8 & 366.42 & 444.67 & 2.143 \\
Circular tube & 6 & 309.33 & 453.67 & 2.087 \\
Beam flange & 11 & 296.33 & 437.00 & 2.105 \\
Beam web & 7 & 280.33 & 421.33 & 2.076 \\
End plate & 12 & 282.72 & 432.41 & 2.103 \\
Reinforcement & 10 & 550.23 & 647.33 & 2.041 \\
\hline
\end{tabular}

horizontal end plate at the bottom flange of the right beam fractured (as shown in Figure 9(b)) at the failure stage of the specimen SBJ1.

3.1.2. Specimen CBJ1. Test specimen CBJ1 was a composite connection with an RC slab of $100 \mathrm{~mm}$ in thickness and web anchorage plates of the nonstiffening type, and the failure modes are shown in Figure 10. Many straight cracks and diagonal cracks can be seen on the entire slab (as shown in Figure 10(a)). The top of the concrete slab was peeled along the serious cracks. And the bottom of the concrete slab was crushed in the core region near the steel tube (as shown in
Figure 10(b)). Because of the presence of the RC slab, the bottom flanges of $\mathrm{CBJ} 1$ were more severely damaged than those of SBJ1, as shown in Figures 10(c) and 10(d).

3.1.3. Specimen CBJ2. Test specimen CBJ2 was a composite connection with an RC slab of $100 \mathrm{~mm}$ in thickness and web anchorage plates of the stiffening type. However, the inner circular tube of the column was not filled in with concrete. The failure modes of specimen CBJ2 are shown in Figure 11. The bottom flange of the left beam suffered severe buckling, as shown in Figure 11(a). The damage began in the welds between the steel tube and the cover plate, and the cracks 


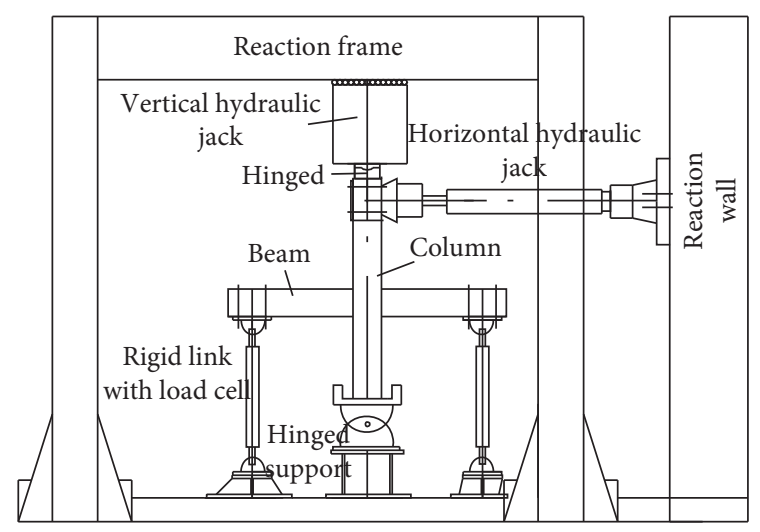

(a)

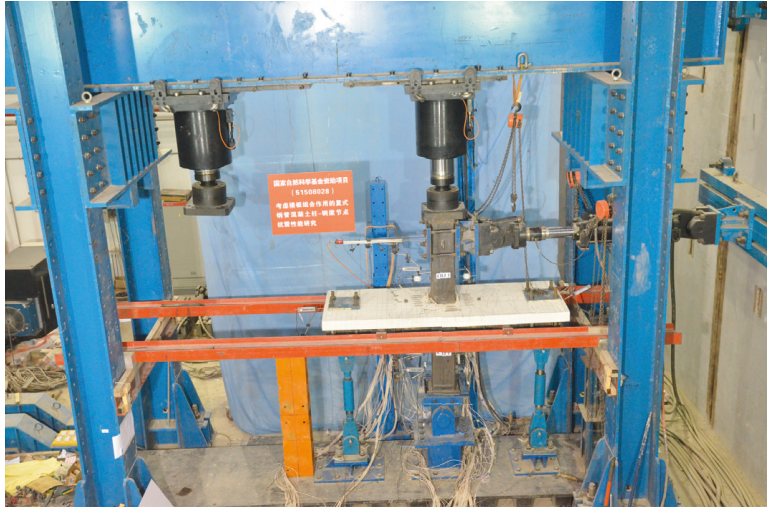

(b)

Figure 5: Test setup: (a) diagram of the loading device; (b) photograph of the loading device.

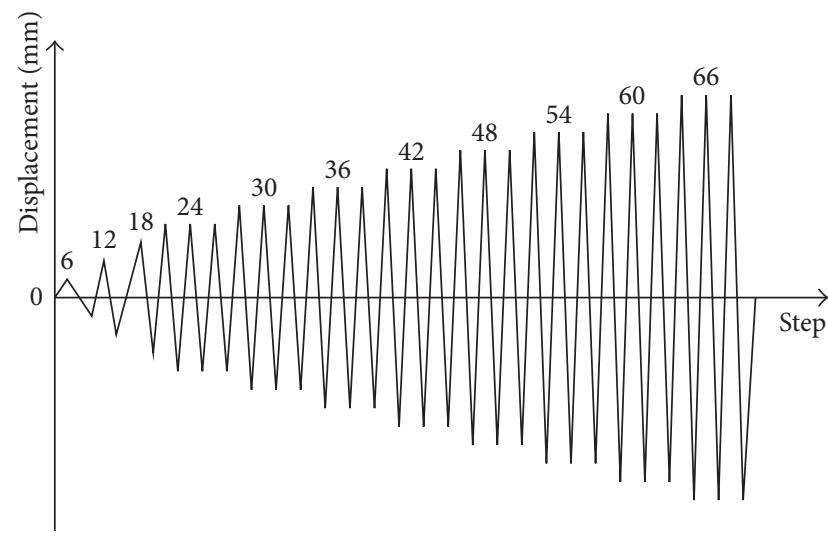

FIGURE 6: Loading history.

developed toward both sides of the tube, to lead the serious buckling on the steel tube wall, as shown in Figures 11(b) and $11(\mathrm{c})$.

3.1.4. Specimen CBJ3. Test specimen CBJ3 was a composite connection with an RC slab of $120 \mathrm{~mm}$ in thickness and web anchorage plates of the stiffening type, and the failure modes are shown in Figure 12. The minor cracking of the weld between the steel tube and the cover plate can be seen (as shown in Figure 12(a)), but that was not the main reason of failure. The weld at the bottom flange of the right beam was completely broken (as shown in Figure 12(b)), which is the main reason of failure of specimen CBJ3.

3.1.5. Specimen CBJ4. Test specimen CBJ4 was a composite joint with an RC slab of $100 \mathrm{~mm}$ in thickness and web anchorage plates of the stiffening type, and the failure modes are shown in Figure 13. The bottom flange of the right beam underwent slight buckling deformation, as shown in Figure 13(a). The weld between the web of the steel tube and the cover plate was fractured and extended to the both sides of steel tube walls, as shown in Figure 13(b), which led to the severe local buckling on the opposite web of the steel tube (as shown in Figure 13(c)). Meanwhile, the weld on the opposite

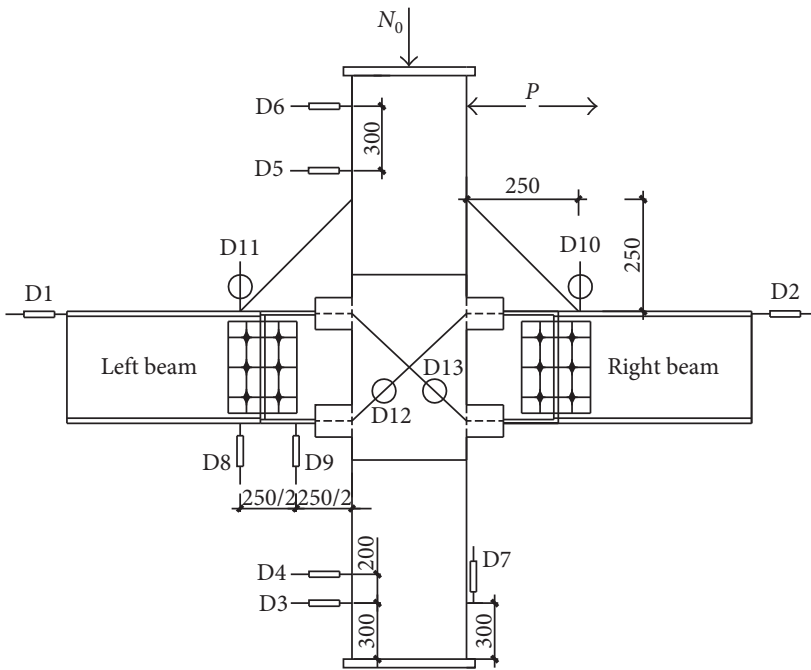

Figure 7: Arrangement of the deformation instrumentation.

steel tube and the cover plate was slightly fractured, as shown in Figure 13(c).

3.1.6. Failure Characteristic. Different failure modes were obtained due to the different constructions of the specimens in the test, and all the specimens' failure modes are shown in Table 3. The specimen SBJ1 failed via a beam-type failure mode and with minor deformation of the flanges of the steel beams, and no damage was observed in the core region of the joint or the column. However, beam-type failure and column-type failure of the specimens considering the effect of the RC slab were obtained in the test. Moreover, the welds at the beams and cover plates were severely damaged. The main reasons were as follows: (1) the neutral axes of these composite joints moved upward due to the presence of the $\mathrm{RC}$ slab, causing the flanges of the steel beams and the welds at the end plates to be severely damaged; (2) the moment was greatly increased because of the composite effect between the steel beam and the RC slab, thus causing additional tensile stress to be carried by the tube and the bottom flange; and (3) 


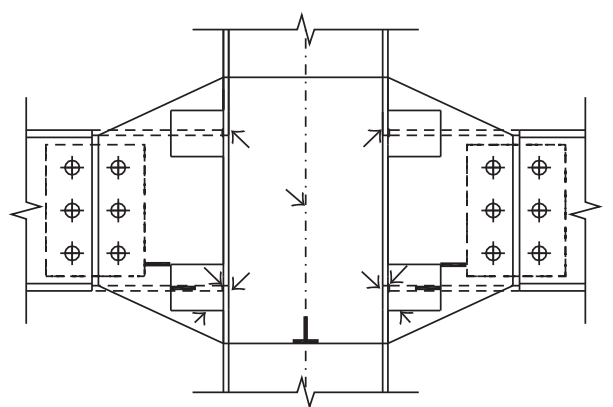

(a)

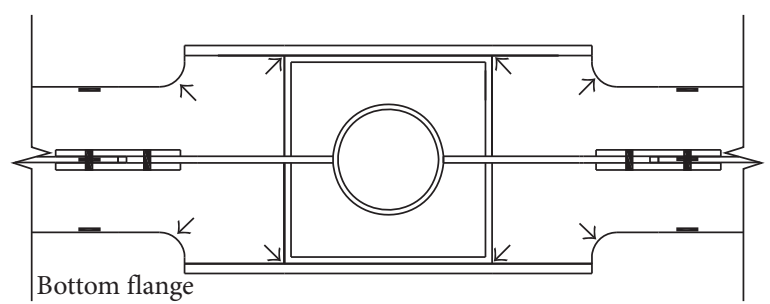

(b)

Figure 8: Arrangement of the strain gauges on the steel components: (a) placed on the stiffening plates and web plates; (b) placed on the flanges and end plates.

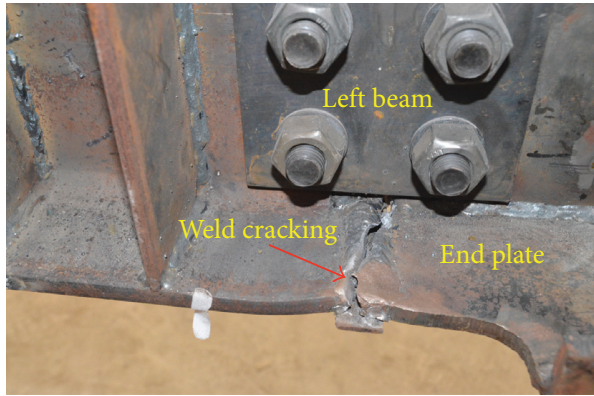

(a)

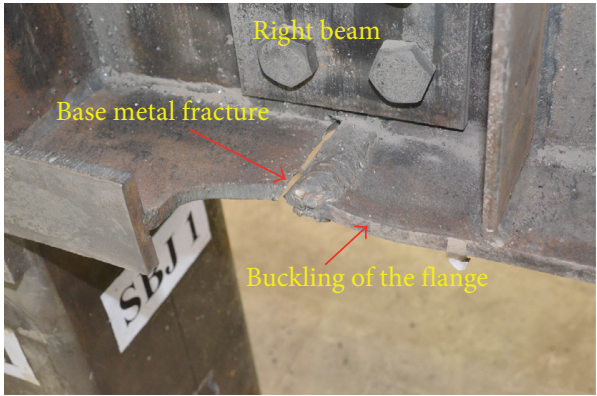

(b)

FIgURE 9: Failure modes of SBJ1: (a) the left beam; (b) the right beam.

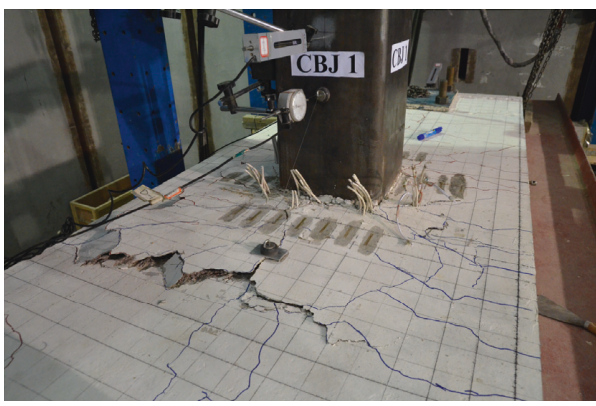

(a)

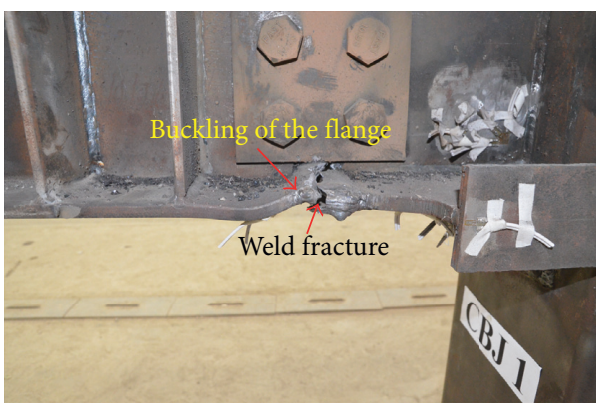

(c)

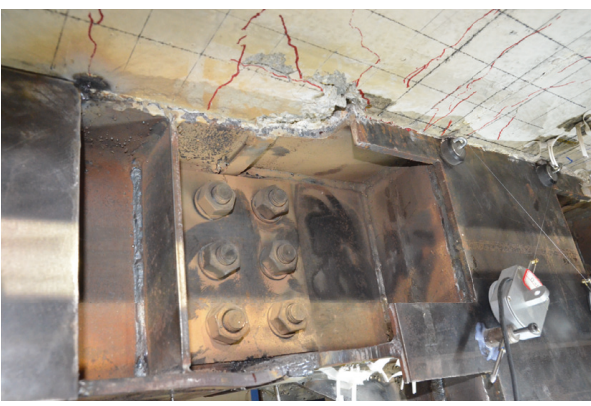

(b)

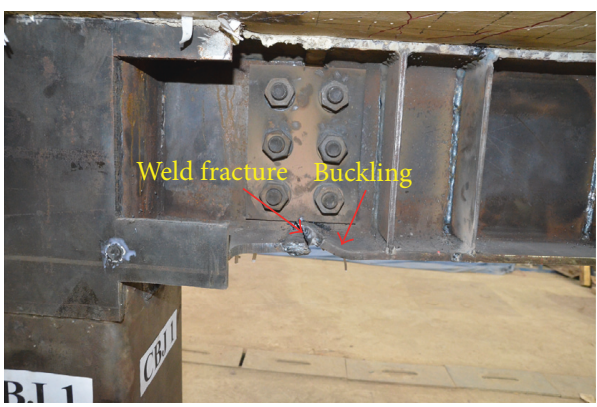

(d)

Figure 10: Failure modes of CBJ1: (a) the top of the slab; (b) the bottom of the slab; (c) the left beam; (d) the right beam. 


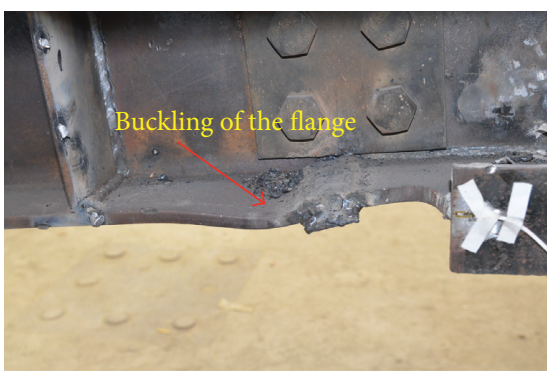

(a)

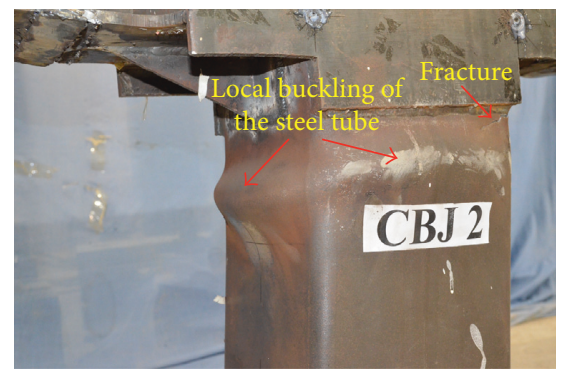

(b)

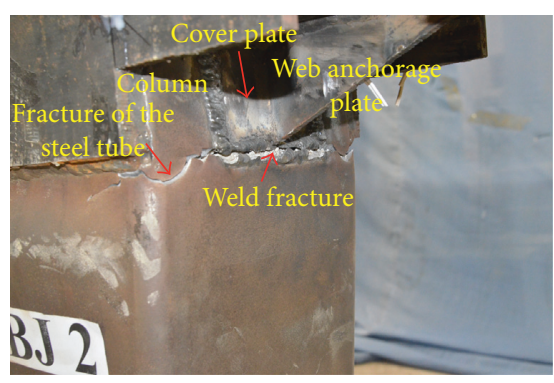

(c)

Figure 11: Failure modes of CBJ2: (a) the left beam; (b) buckling of the column; (c) weld fracture of the tube.

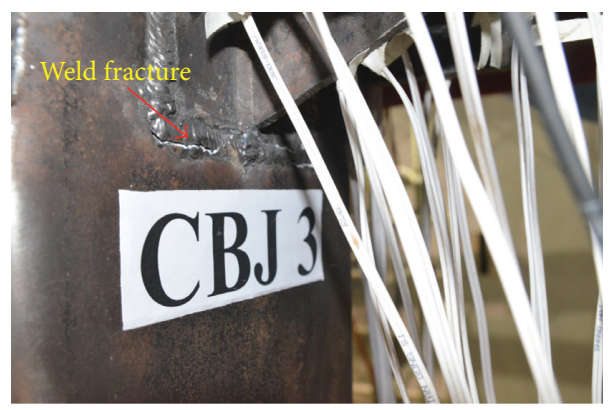

(a)

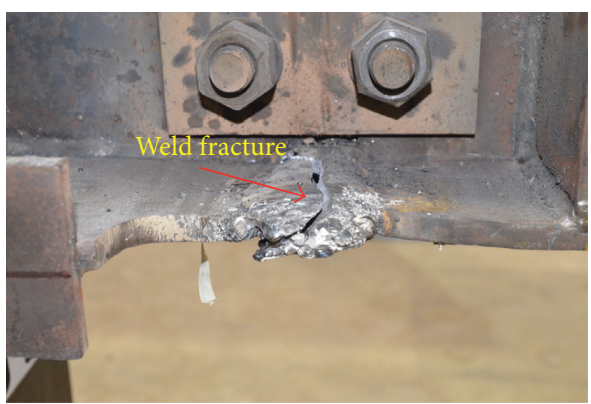

(b)

FIGURE 12: Failure modes of CBJ3: (a) the steel tube; (b) the right beam.

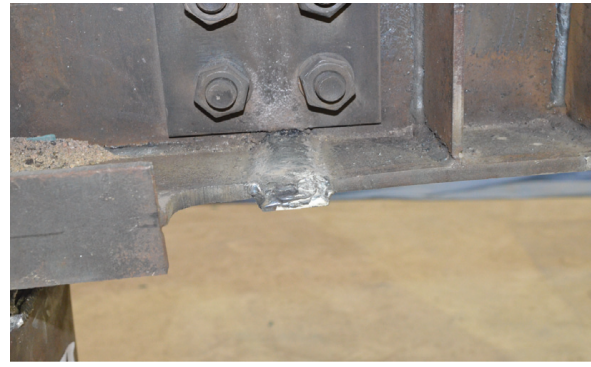

(a)

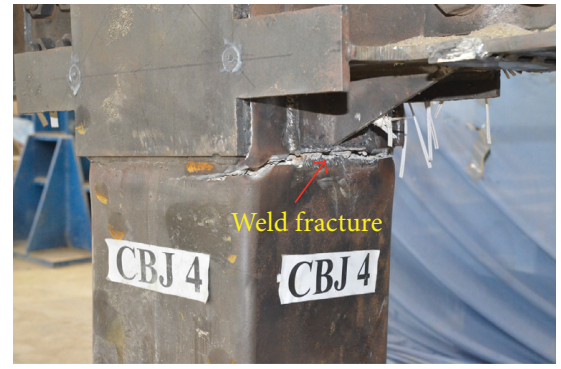

(b)

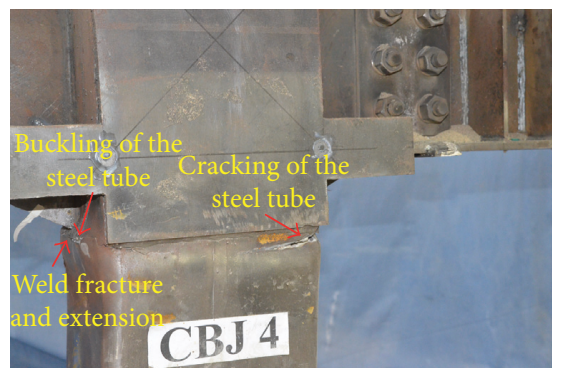

(c)

FIGURE 13: Failure modes of CBJ4: (a) the right beam; (b) weld fracture at the steel tube; (c) buckling of the steel tube.

significant stress concentrations formed at the cover plate welds because these plates were placed close to the web anchorage plates of the stiffening type, which resulted in the development of cracks and buckling deformation of the tube.
In engineering practice, an RC slab can protect the top flange of a steel beam but will aggravate the damage to the bottom flange, especially the damage to the welds at the bottom flange. Therefore, to ensure the desired seismic 
TABLE 3: All the specimens' failure modes.

\begin{tabular}{lccccc}
\hline Failure modes & SBJ1 & CBJ1 & CBJ2 & CBJ3 & CBJ4 \\
\hline Beam-type failure & Yes & Yes & Yes & Yes & - \\
Column-type failure & - & - & Yes & - & Yes \\
\hline
\end{tabular}

performance, composite joints of this type should be designed with smaller top flanges and larger bottom flanges. For the specimens that exhibited column failures, such failures occurred because the ratios of the beam-column stiffness and the beam-column bending resistance were both increased by the presence of the RC slab. This column-type failure mode needs to be avoided in structural design by appropriately modulating the ratios of stiffness and bending resistance. Furthermore, the cover plates need to be placed farther from the web anchorage plates to avoid the concentration of stress.

3.2. Hysteresis Curves. The hysteresis curve is an important characteristic representing the seismic performance of a structure. Figure 14 shows the load-displacement hysteresis curves of the test specimens. It was found that the specimens exhibited shuttle-shaped hysteresis curves, and they demonstrated good energy dissipation capabilities, as shown by their sufficient envelope areas. The shapes of the hysteresis curves for the composite joints varied from a shuttle shape to an arc shape or a reversed $\mathrm{S}$ shape, except for CBJ2, when the ultimate strength was reached. The main reason is that the maximum tensile stress on the bottom flanges of the steel beams increased as the lateral force on the column increased, causing cracks to develop and spread quickly, which resulted in stiffness degradation of the joint and little pinching effect on the hysteresis curves of specimens. By contrast, the welds at the beam flanges of CBJ2 did not fracture during the whole loading. Consequently, there was no pinching effect on the hysteresis curve for specimen CBJ2. Some sharp drops are evident in the hysteresis curves due to the fracturing of the steel plates or welds during the loading process. Additionally, the slopes of the loading curves for the specimens decreased with increasing lateral load, but the slopes of the unloading curves showed no obvious changes, indicating that the specimens were more severely damaged during later loading stages.

3.3. Skeleton Curves. The skeleton curves of tested specimens were plotted by connecting the maximum load points of the hysteretic curves at each displacement level. The yield strength, yield displacement, ultimate strength, and ultimate displacement of these specimens can be determined from the skeleton curves. Figure 15 shows the $P-\Delta$ skeleton curves of the tested specimens under different experimental parameters. And the following conclusions can be drawn:

(1) The specimens experienced elastic, elastic-plastic, and damage stages. Compared with Figure 15(a), the slope and ultimate strength of CBJ4 were larger than those of SBJ1, with increases in the ultimate strength of $56 \%$ and $17 \%$ in the positive and negative directions, respectively. These findings indicate that the presence of an RC slab effectively strengthens a joint, and thus, the composite action exerted by an RC slab cannot be ignored during structural design.

(2) According to Figure 15(b), the ultimate strength of CBJ4 was increased by $30 \%$ and $19 \%$ in comparison with CBJ1 in the positive and negative directions, respectively. Furthermore, the ultimate displacement of CBJ4 was similarly increased by $25 \%$ and $14 \%$. These findings indicate that stiffening-type web anchorage plates effectively enhance the stiffness and strength of a joint and can protect the bottom flanges of the steel beams.

(3) The skeleton curve of CBJ2 is similar to that of CBJ4, as seen from Figure 15(c), indicating that the infilled concrete makes a very small contribution to the initial stiffness and strength of a composite joint.

(4) The initial stiffness of CBJ3 was markedly higher than that of CBJ4 because of the greater thickness $(120 \mathrm{~mm})$ of the RC slab in CBJ3, as shown in Figure 15(d). The experimental findings suggest that the initial stiffness of a composite joint can be modulated by varying the thickness of the RC slab. However, the ultimate strength of the joint with the higher RC slab thickness was lower because of the increase in the maximum stress on the bottom flanges of the steel beams caused by the increased thickness of the RC slab. Thus, it can be concluded that the composite action of the RC slab can be enhanced by increasing its thickness but doing so aggravates the damage to the flanges of the steel beams.

3.4. Strength and Ductility. To evaluate quantitatively the seismic resistance of the new type of joints of CFDST columns to steel beams with RC slabs, the characteristic points from the $P-\Delta$ skeleton curves were captured in accordance with Tang et al. [13], as shown in Figure 16. $P_{\mathrm{y}}, P_{\mathrm{m}}$, and $P_{\mathrm{u}}$ are the yield strength, the ultimate strength, and the damage strength, respectively, of the specimen. The corresponding yield displacement, ultimate displacement, and damage displacement are denoted by $\Delta_{\mathrm{y}}, \Delta_{\mathrm{m}}$, and $\Delta_{\mathrm{u}}$, respectively. The damage strength $P_{\mathrm{u}}$ is defined to be equal to $0.85 P_{\mathrm{m}}$. The detailed results for the strength and displacement values of the specimens at these key points are presented in Table 4. According to Table 4, the joint strength was enhanced by the composite action of an RC slab.

High-ductility structures possess an excellent plastic deformation capability and thus can avoid brittle failure, providing the occupants of a building with sufficient time to escape in the case of an earthquake or some other disasters. Therefore, the ductility is an important aspect to consider when evaluating the seismic performance of a structure. The displacement ductility coefficient $(\mu)$ is adopted here to analyze the overall ductility of the new type of composite connection investigated in this study. The displacement ductility coefficient $(\mu)$ is calculated as the ratio of the 

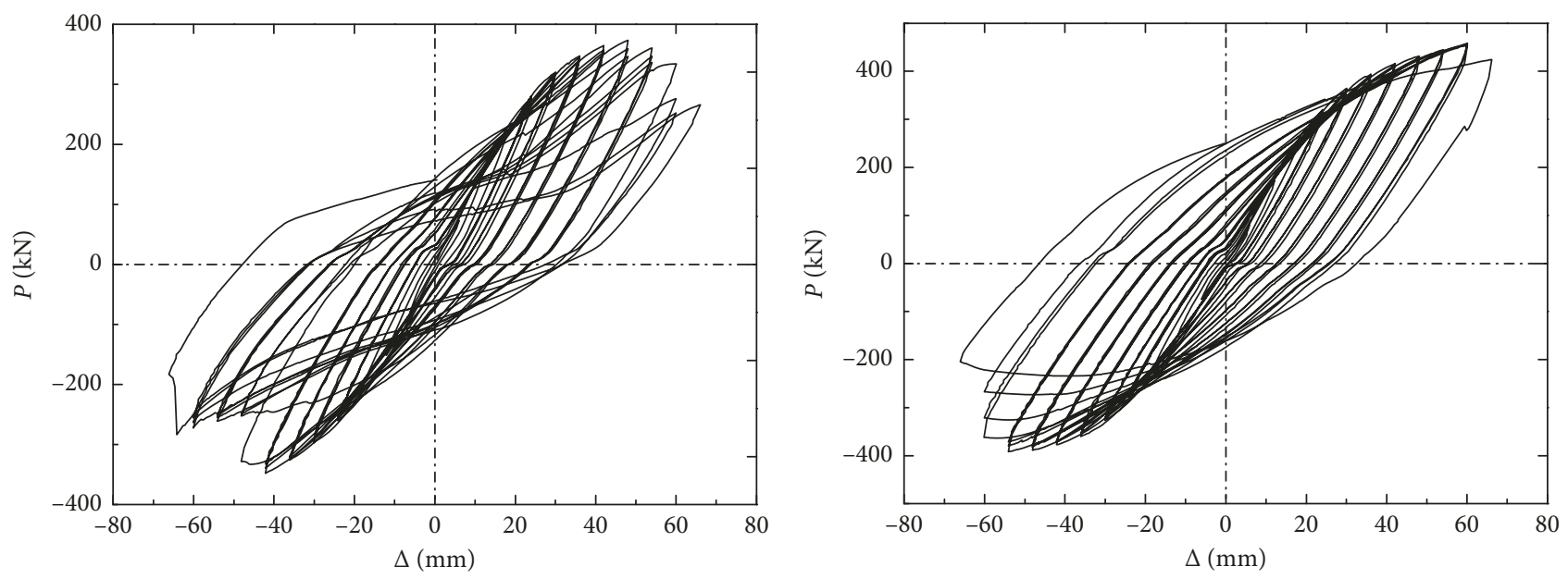

- $\mathrm{CBJ1}$

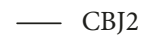

(a)
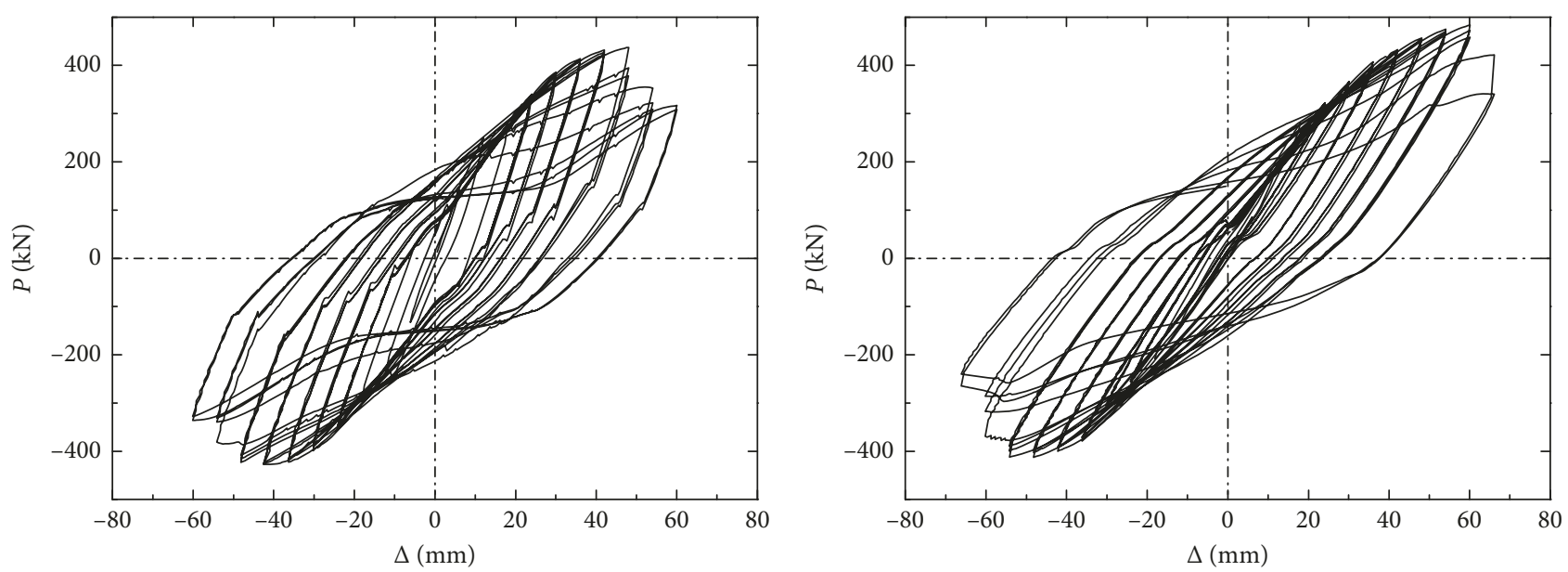

- CBJ3

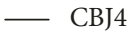

(c)

(d)

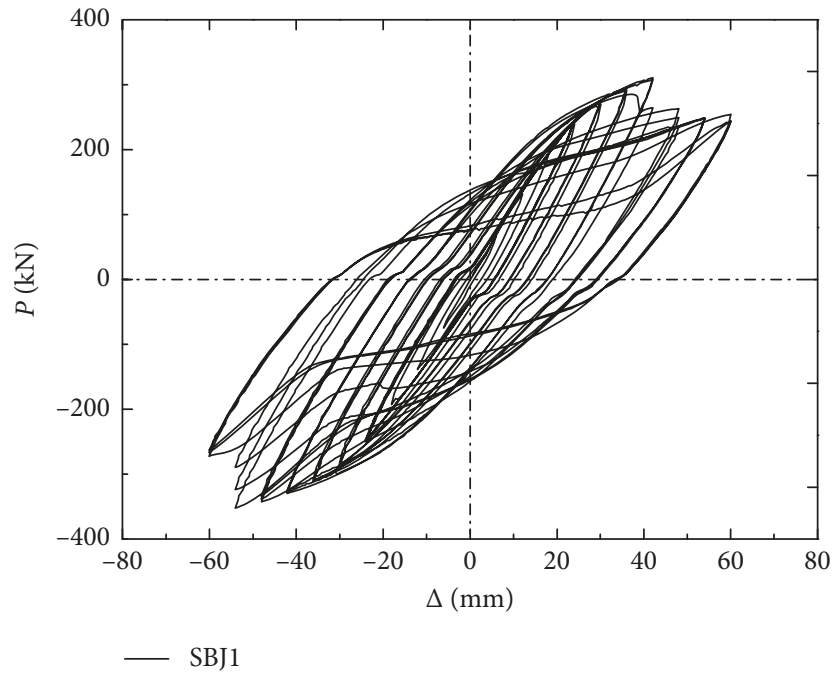

(e)

Figure 14: P- $\triangle$ hysteresis loops of the end of the column: (a) CBJ1; (b) CBJ2; (c) CBJ3; (d) CBJ4; (e) SBJ1. 

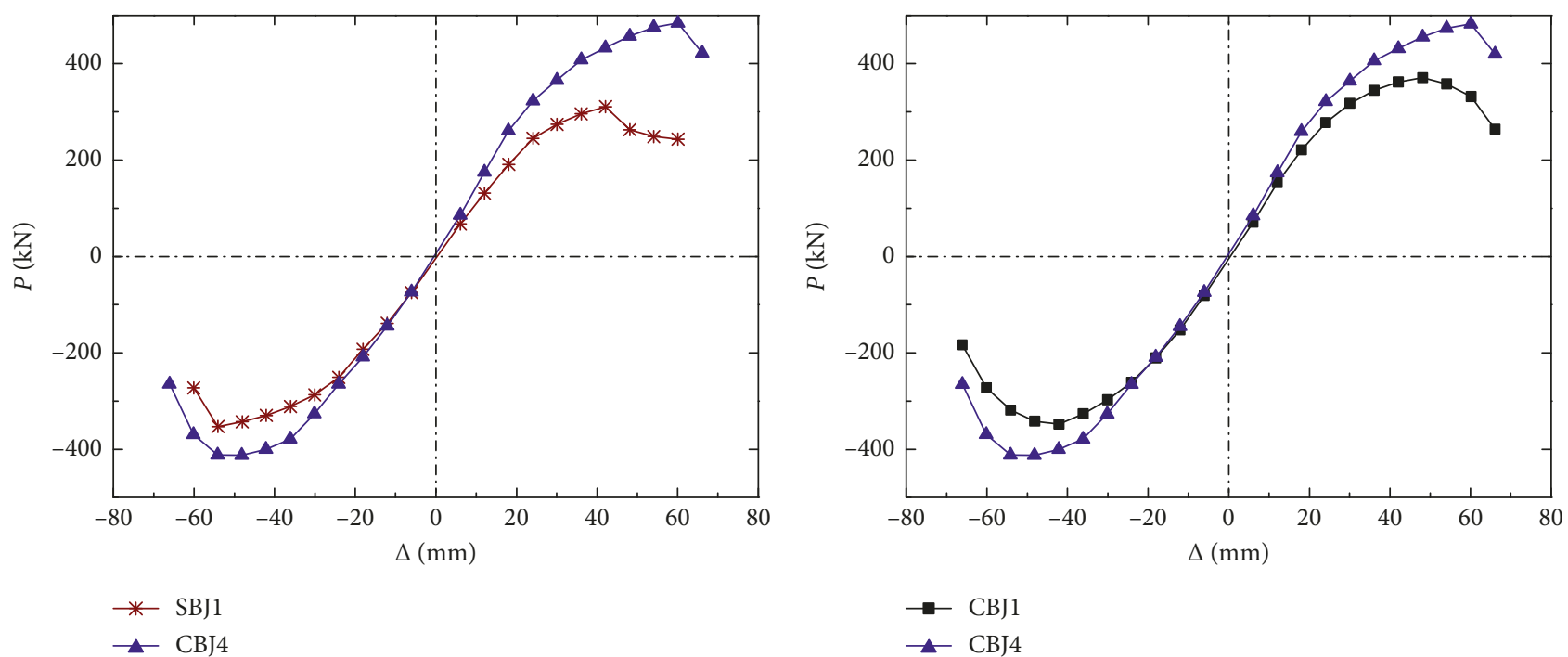

(a)

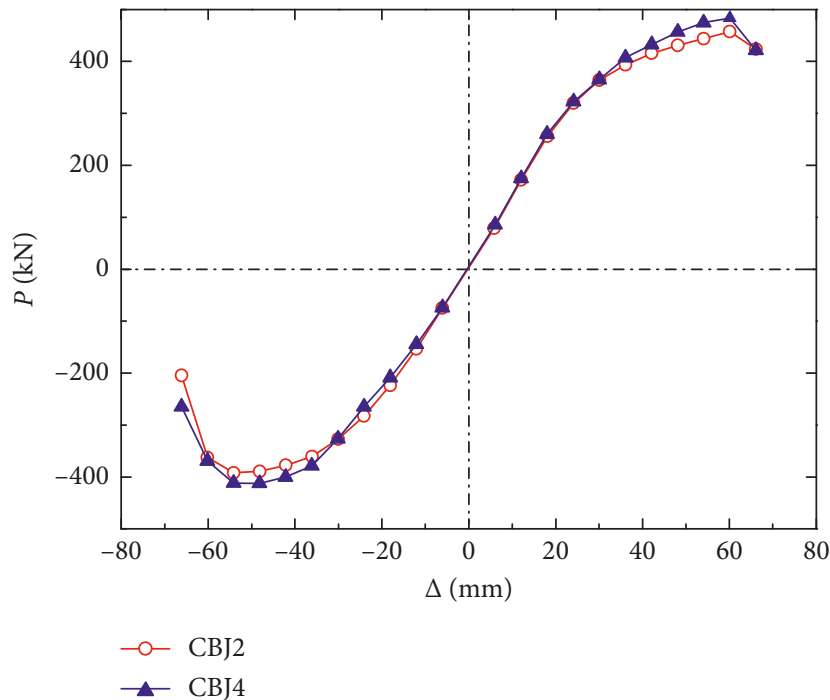

(c)

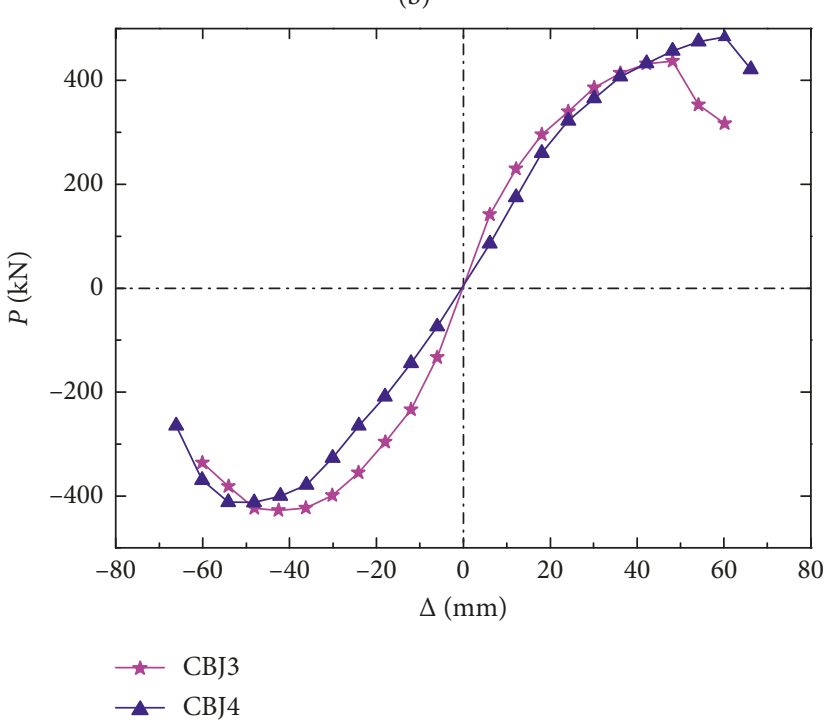

(d)

Figure 15: P- $\Delta$ envelope curves of the specimens: (a) effect of the RC slab; (b) effect of the stiffening of the web anchorage plates; (c) effect of the infilled concrete; (d) effect of the thickness of the RC slab.

displacement in the failure state $\left(\Delta_{\mathrm{u}}\right)$ to the displacement in the yielding state $\left(\Delta_{\mathrm{y}}\right)$; the formula is shown as follows:

$$
\mu=\frac{\Delta_{\mathrm{u}}}{\Delta_{\mathrm{y}}}
$$

The ductility coefficients $(\mu)$ of the tested composite connections, which are listed in Table 5, are all within the range of 2.00 2.89. Detailed ductility regulations are not presently specified in the 138-2016 code [14] or the GB50011 code [15].

The interstory drift ratio $(\theta)$ is also a significant index for checking the deformation of structures during seismic design. This index is defined as $\theta=\arctan \left(\Delta_{\mathrm{H}} / H\right)$, where $\Delta_{\mathrm{H}}$ is the lateral drift at the top of the column and $H$ is the height between the top of the column and the hinge at the bottom of the column. In Table 5, $\theta_{\mathrm{y}}$ and $\theta_{\mathrm{u}}$ are the yield drift ratio and the damage drift ratio, respectively. According to the definition of the limit value of the drift ratio given in CECS 159: 2004 [16] for midrise and high-rise CFST frames, the limit values are $\left[\theta_{\mathrm{e}}\right]=1 / 250$ and $\left[\theta_{\mathrm{p}}\right]=1 / 50$ for the elastic stage and the elastic-plastic stage, respectively. The results for the specimens in this study are, respectively, $\theta_{\mathrm{y}}=(2.87-4.93)$ $\left[\theta_{\mathrm{e}}\right]$ and $\theta_{\mathrm{u}}=(1.11-1.52)\left[\theta_{\mathrm{p}}\right]$. Moreover, the ductility coefficients of the specimens had values of 2.00 to 2.89 , which meet or exceed the value of 2.0 defined in the Chinese standard. The elastic interstory drift ratios of the composite joints are larger than the limit value, whereas the elasticplastic interstory drift ratios exceed slightly the limit value. Because the welds of the composite joints were fractured in the damage stage, the $\theta_{\mathrm{u}}$ values were smaller than the desired value. Thus, to enhance the ductility of CFDST structures, 


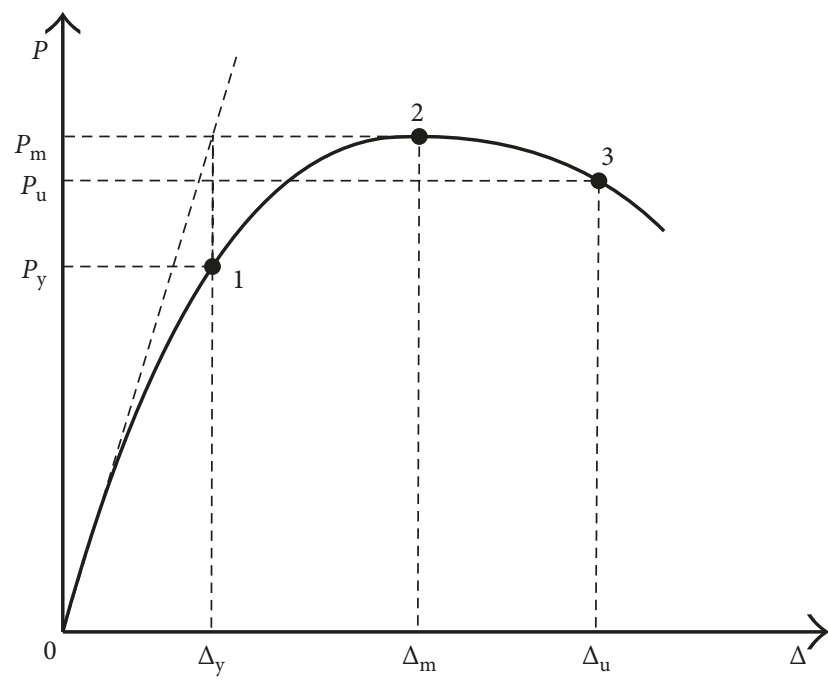

Figure 16: Key points on the skeleton curve.

TABLE 4: Experimental results.

\begin{tabular}{lcccccc}
\hline & \multicolumn{3}{c}{ Yielding point } & \multicolumn{2}{c}{ Maximum point } & \multicolumn{2}{c}{ Failure point } \\
Specimen & $\Delta_{\mathrm{y}}$ & $P_{\mathrm{y}}$ & $\Delta_{\mathrm{m}}$ & $P_{\mathrm{m}}$ & $\Delta_{\mathrm{u}}$ & $P_{\mathrm{u}}$ \\
& $(\mathrm{mm})$ & $(\mathrm{kN})$ & $(\mathrm{mm})$ & $(\mathrm{kN})$ & $(\mathrm{mm})$ & $(\mathrm{kN})$ \\
\hline SBJ1 (+) & 28.50 & 270 & 42.09 & 310.43 & 60 & 263.86 \\
SBJ1 (-) & 28.44 & 280 & 54.08 & 352.55 & 60 & 299.67 \\
CBJ1 (+) & 28.96 & 311 & 48.09 & 372.33 & 62 & 316.48 \\
CBJ1 (-) & 27.05 & 280 & 42.08 & 347.77 & 57.5 & 295.60 \\
CBJ2 (+) & 32.09 & 378 & 60.08 & 457.60 & 66 & 388.96 \\
CBJ2 (-) & 30.80 & 327 & 54.15 & 391.97 & 61.5 & 333.18 \\
CBJ3 (+) & 18.69 & 300 & 48.08 & 437.90 & 53 & 372.22 \\
CBJ3 (-) & 19.37 & 306 & 42.55 & 427.29 & 56 & 363.2 \\
CBJ4 (+) & 30.26 & 392 & 60.07 & 484.26 & 66 & 411.62 \\
CBJ4 (-) & 30.99 & 363 & 48.15 & 412.11 & 64 & 350.29 \\
\hline
\end{tabular}

the weld-damage failure mode must be avoided in structure design. The principles of "strong column, weak beam" and "strong joint, weak component" define the desired failure modes: plastic hinges should form first at the beam ends and then at the column ends. However, it is still difficult to achieve this ideal failure mechanism in such structures because of their complex behavior. Work is currently ongoing with a focus on controlling the failure modes of CFDST structures by adjusting the construction of the joints.

3.5. Stiffness Degradation. The stiffness of a structure degrades with an increasing number of load cycles; this behavior is called stiffness degradation. In this paper, the average loop stiffness $K_{j}$ is used to evaluate the stiffness degradation of the specimens, and $K_{j}$ is defined in the Chinese standard JGJ/T 101-2015 [12] as follows:

$$
K_{j}=\frac{\sum_{i=1}^{n} P_{j}^{i}}{\sum_{i=1}^{n} \Delta_{j}^{i}},
$$

where $P_{j}^{i}$ and $\Delta_{j}^{i}$ are the peak load and the corresponding displacement of the $i$ th cycle when the displacement control reaches to $j$, and $n$ is the number of cycles.
TABLE 5: Ductility coefficients and energy dissipation of the specimens.

\begin{tabular}{lccccccc}
\hline Specimen & $\begin{array}{c}\Delta_{\mathrm{y}} \\
(\mathrm{mm})\end{array}$ & $\begin{array}{c}\Delta_{\mathrm{u}} \\
(\mathrm{mm})\end{array}$ & $\begin{array}{c}\theta_{\mathrm{y}} \\
(\mathrm{rad})\end{array}$ & $\begin{array}{c}\theta_{\mathrm{u}} \\
(\mathrm{rad})\end{array}$ & $\mu$ & $h_{\mathrm{e}}$ & $E$ \\
\hline SBJ1 (+) & 28.50 & 60 & 0.0144 & 0.0304 & 2.11 & 0.302 & 1.895 \\
SBJ1 (-) & 28.44 & 60 & 0.0144 & 0.0304 & 2.11 & & \\
\hline CBJ1 (+) & 28.96 & 62 & 0.0147 & 0.0314 & 2.14 & 0.284 & 1.782 \\
CBJ1 (-) & 27.05 & 57.5 & 0.0137 & 0.0291 & 2.13 & & \\
\hline CBJ2 (+) & 32.09 & 66 & 0.0163 & 0.0334 & 2.06 & 0.282 & 1.772 \\
CBJ2 (-) & 30.80 & 61.5 & 0.0156 & 0.0311 & 2.00 & & \\
\hline CBJ3 (+) & 18.69 & 53 & 0.0095 & 0.0268 & 2.83 & 0.311 & 1.957 \\
CBJ3 (-) & 19.37 & 56 & 0.0098 & 0.0284 & 2.89 & & \\
\hline CBJ4 (+) & 30.26 & 66 & 0.0153 & 0.0334 & 2.18 & 0.311 & 1.954 \\
CBJ4 (-) & 30.99 & 64 & 0.0157 & 0.0324 & 2.07 & & \\
\hline
\end{tabular}

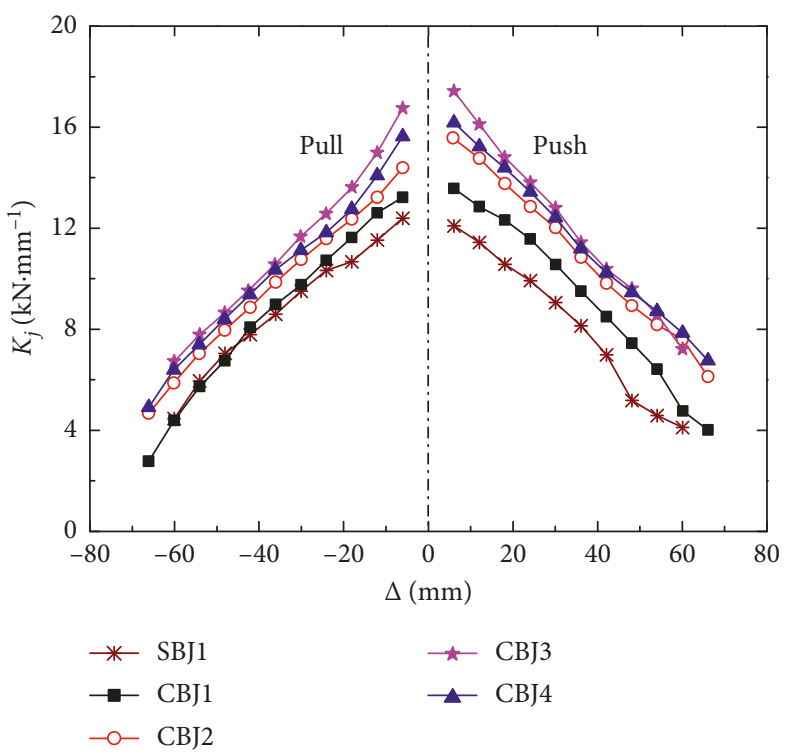

FIgURE 17: Stiffness degradation curves.

Figure 17 shows the stiffness degradation curves of the joint specimens. The stiffness of each specimen markedly degraded throughout the loading process. The stiffness of the composite joints was higher than that of the joint without an RC slab. Specimen CBJ3 had the highest stiffness, followed by $\mathrm{CBJ} 4, \mathrm{CBJ} 2$, and $\mathrm{CBJ} 1$, indicating that the stiffness of a composite joint can be effectively increased by an RC slab and stiffening-type web anchorage plates.

3.6. Bearing Capacity Degradation. The strength of a structure also degrades with an increasing number of load cycles. The strength degradation coefficient at the ith loading level, $\lambda_{i}$, and the total strength degradation coefficient, $\lambda_{j}$, are both used in this paper to investigate the strength degradation behavior of the specimens in accordance with the Chinese standard JGJ/T 101-2015 [12]. At the same loading level, $\lambda_{i}$ is the ratio of the maximum strength in each cycle to the maximum strength in the first cycle. By contrast, $\lambda_{j}$ is the ratio of the maximum strength at each loading level to the maximum strength throughout the entire loading 


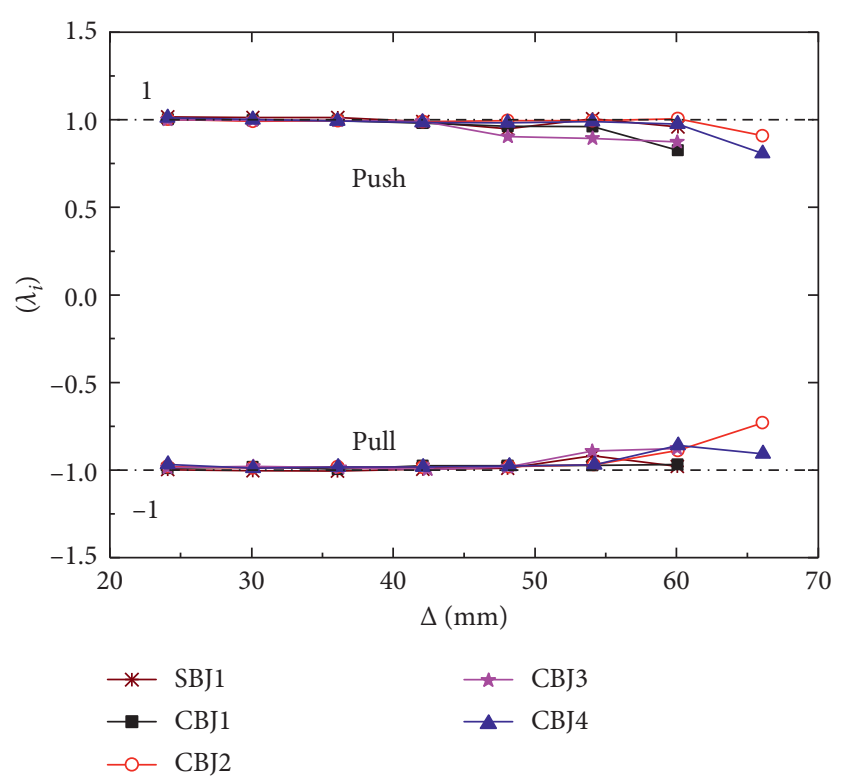

(a)

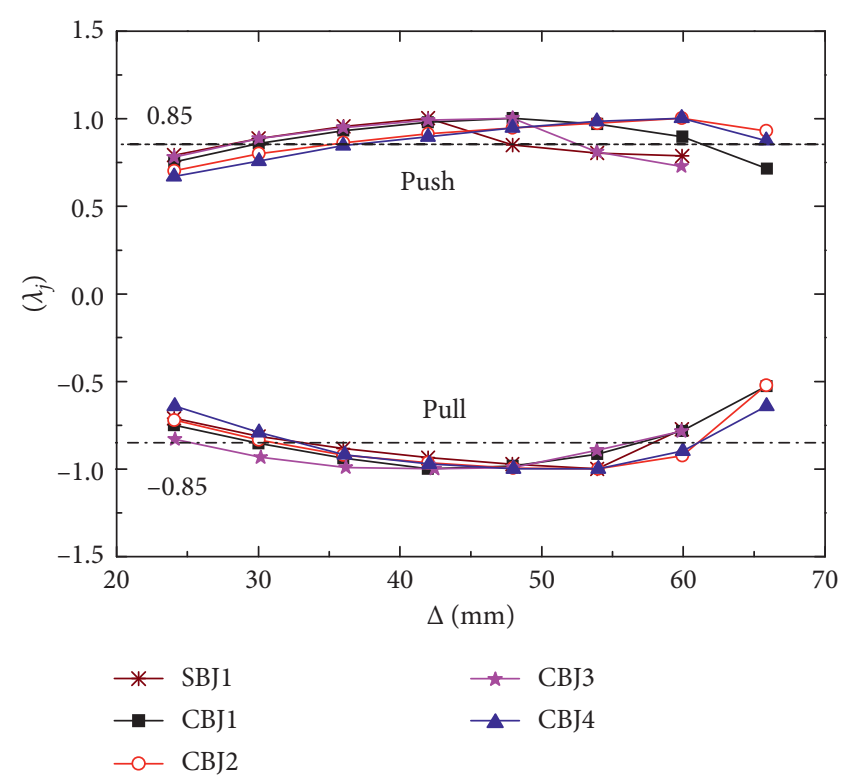

(b)

FIGURE 18: Strength degradation curves: (a) strength degradation at the same loading level; (b) overall strength degradation.

process. The strength degradation curves of the specimens are shown in Figure 18.

According to Figure 18(a), each of the $\lambda_{i}$ curves has a long approximately horizontal segment corresponding to when the yield strength of the specimen was reached, indicating that these specimens exhibited good elastic-plastic performance. The strength of each specimen slightly decreased when the peak strength was reached, and it decreased considerably in the damage stage. According to Figure 18(b), the degree of strength degradation when a specimen was subjected to a negative load was slightly larger than that under a positive load. The strength degradation coefficients of most of the specimens were larger than 0.85 when the peak load was reached, indicating that no obvious strength degradation occurred in the elastic and elastic-plastic stages; however, marked strength degradation occurred in the damage stage, as the weld of the beam bottom flange or the cover plate connected to the column wall was fractured at the failure displacement.

3.7. Energy Dissipation. The energy dissipation capacity is another important aspect to consider when evaluating the seismic performance of a structure. In this paper, the equivalent damping coefficient $\left(h_{\mathrm{e}}\right)$ and the energy dissipation coefficient $(E)$ presented in the Chinese standard JGJ/T 101-2015 [12] are used to evaluate the energy dissipation of the joint specimens. In general, the larger these coefficients are, the better the energy dissipation capacity is. The equivalent damping coefficient $\left(h_{\mathrm{e}}\right)$ was defined by (3), and Figure 19 illustrated the parameters of (3). $S_{\mathrm{BEF}}$ and $S_{\mathrm{DEF}}$ are, respectively, areas of the hysteresis loop of BEF and $\mathrm{DEF}$, and $S_{\mathrm{AOB}}$ and $S_{\mathrm{COD}}$ are, respectively, triangle areas of $\mathrm{AOB}$ and $\mathrm{COD}$. The energy dissipation coefficient $(E)$ was calculated by $E=2 \pi h_{\mathrm{e}}$ :

$$
h_{\mathrm{e}}=\frac{1}{2 \pi} \frac{S_{\mathrm{BEF}}+S_{\mathrm{DEF}}}{S_{\mathrm{AOB}}+S_{\mathrm{COD}}}
$$

The equivalent damping coefficient $\left(h_{\mathrm{e}}\right)$ and the energy dissipation coefficient $(E)$ of the tested specimens are listed in Table 4. By comparing these coefficients for SBJ1 and CBJ4, it can be found that the energy dissipation capacity of the joint specimen with the RC slab was better than that of the bare steel joint specimen without the RC slab. However, the result of Liao et al. [9] is that the $h_{\mathrm{e}}$ values of the joint specimen with the RC slab were almost half of the joint specimen without the RC slab. Comparing the current research with Liao et al. [9], it indicates that the energy dissipation capacity of the composite joint is closely related to the construction details of the joint. By comparing CBJ4 with $\mathrm{CBJ} 1$ and $\mathrm{CBJ} 2$, respectively, the energy dissipation capacity of a joint can be effectively enhanced by using stiffening-type web anchorage plates and by filling the column with concrete. It can be seen from Table 4 that the $h_{\mathrm{e}}$ values of the specimens ranged from 0.282 to 0.311 , larger than the value for an RC joint (approximately 0.1) and similar to the value for a steel-reinforced concrete joint (approximately 0.3). Test results reported by Zeng et al. [17] on concrete-encased composite frame joints under cyclical loadings indicate that $h_{\mathrm{e}}$ ranges from 0.20 to 0.32 . Compared with Zeng et al. [17], it seems $h_{\mathrm{e}}$ values of the joint specimens in this study are similar to those in their study. Han and Li [10] reported the test results of the CFST column to steel beam joints with RC slabs, which indicate $h_{\mathrm{e}}$ values ranged from 0.175 to 0.23 . Compared with Han and Li [10], it seems that the energy dissipation capacity of a composite joint of the CFDST column is a bit better favorable than that of a composite joint of the CFST column. Therefore, the construction of the proposed new type of composite joint in 


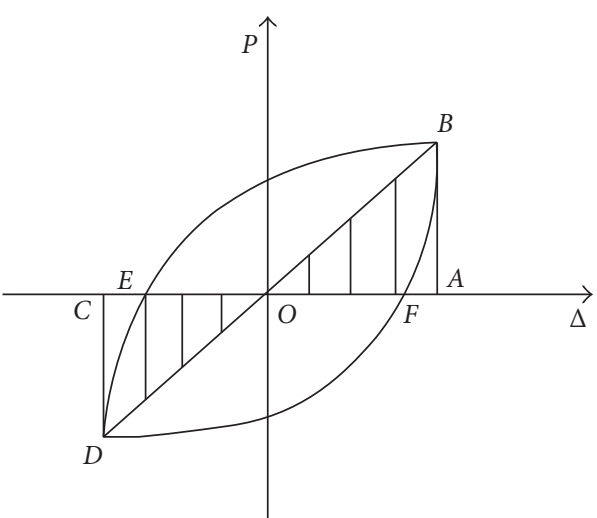

FIgURE 19: Idealized $P-\Delta$ hysteretic relation.

this study is reasonable due to the favorable energy dissipation capacity.

Figure 20 shows the curves relating the accumulated energy dissipation $\left(E_{t}\right)$ to the number of cycles $(n)$ for these specimens. As the number of cycles $(n)$ increased, the accumulated energy dissipation $\left(E_{\mathrm{t}}\right)$ of each specimen also generally increased steadily. The growth rate of the accumulated energy dissipation $\left(E_{\mathrm{t}}\right)$ began to decrease for CBJ1 and SBJ1 at the number of cycle $(n=17)$. Because SBJ1 was a bare steel beam joint without an RC slab, the energy dissipation capacity decreased with the fracturing of the bottom flanges of the steel beams in the damage stage. For $\mathrm{CBJ} 1$, the fracturing of the bottom flanges of the steel beams resulted in the strength degradation of the specimen in the damage stage. However, the new type of joints of CFDST columns to steel beams considering an RC slab showed excellent seismic performance in terms of ductility, equivalent damping factor $\left(h_{\mathrm{e}}\right)$, and accumulated energy dissipation capacity $\left(E_{\mathrm{t}}\right)$.

\section{Conclusions}

A series of cyclic loading experiments performed on steelbeam-to-CFDST-column joints with RC slabs were reported in this paper. The conclusions obtained based on these discussions are summarized as follows:

(1) The composite joints proposed in this paper for connecting CFDST columns to steel beams supporting concrete slabs exhibit better performance in terms of loading capacity, lateral stiffness, ductility, and energy dissipation in comparison with bare steel joints. Moreover, such composite joints conform to the design principle of "strong joint, weak component" to promote a beam-hinge failure mode. The construction of the composite joints is reasonable because the vertical stiffening plates protect the core regions of the joints, whereas the anchorage plates can effectively transfer vertical loads from the columns to the beam webs and mitigate the buckling deformation of the bottom flanges of the beams.

(2) The bearing capacity of the joint was found to be increased by $56 \%$ and $17 \%$ in the positive and negative

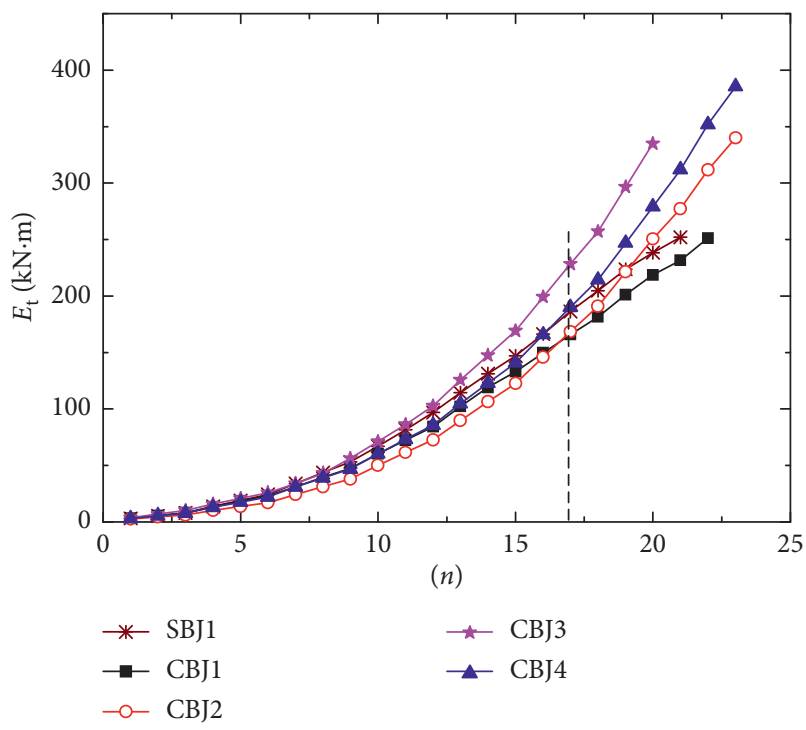

FIgURe 20: Accumulated energy dissipation.

directions, respectively, by the composite action of an $\mathrm{RC}$ slab, indicating that this composite action is more effective in enhancing the positive bending resistance of a joint. With the use of stiffening-type web anchorage plates, the joint strength was increased by $30 \%$ and $19 \%$ in the positive and negative directions, respectively, and the ultimate displacement was similarly increased by $25 \%$ and $14 \%$. These findings also indicate that it is necessary to strength the bottom flanges of the steel beams in the proposed composite joints.

(3) Although both the stiffness and strength of a CFDST joint can be effectively enhanced by the composite action of an RC slab, this composite action can also intensify the stress acting on the bottom flanges of the steel beams and change the beam-column stiffness ratio. Consequently, the failure modes of these composite joints may shift from beam failure to column failure, as seen for specimen CBJ2 in this paper. Thus, the column strength and stiffness need to be properly designed considering the properties of composite beams.

(4) Stable hysteresis curves and good ductility were observed in the composite joints under load cycling. The specimens showed marked stiffness degradation but no obvious strength degradation. And the accumulated energy dissipation stably increased throughout the loading process. Moreover, both the elastic interstory drift ratio and the elastic-plastic interstory drift ratio were found to satisfy the requirements specified by the relevant design standards. All these findings indicate that the new type of composite connections show excellent ductility and favorable energy dissipation and can be effectively utilized in superhigh-rise buildings erected in earthquake zones.

Further finite element analysis and theoretical investigation on the mechanical properties of the new type of the composite joint are planned by the authors. 


\section{Data Availability}

The data of the study were obtained by the experiment which can be verified and replicated when the same test will be carried out. And in this study, the figures on the test data analysis are all drawn in Origin 7.5. And the raw data can be found in the figures, such as hysteresis curves, skeleton curves, and stiffness degradation. Meanwhile, some data of the calculation process are all according to the standard regulations, listed on the references, which is simple and clear for the readers of civil engineering.

\section{Conflicts of Interest}

The authors declare that there are no conflicts of interest related to this study.

\section{Acknowledgments}

This study was financially supported by the National Natural Science Foundation of China (NSFC) (Grant no. 51508028), Natural Science Foundation of Shaanxi Province (Grant no. 2018JQ5119), China Postdoctoral Science Foundation (Grant nos. 2014M562357 and 2015M580803), Special Fund for Basic Scientific Research of the Central Colleges (Grant nos. 300102288112 and 310828173402), and Postdoctoral Research Project of Shaanxi Province.

\section{References}

[1] L.-H. Han, H. Huang, and X.-L. Zhao, "Analytical behaviour of concrete-filled double skin steel tubular (CFDST) beamcolumns under cyclic loading," Thin-Walled Structure, vol. 47, no. 6-7, pp. 668-680, 2009.

[2] Q.-Q. Liang, "Nonlinear analysis of circular double-skin concrete-filled steel tubular columns under axial compression," Engineering Structure, vol. 131, pp. 639-650, 2017.

[3] Y.-F. Zhang and D.-F. Zhang, "Experimental study on the seismic behaviour of the connection between concrete- filled twin steel tubes column and steel beam," European Journal of Environmental and Civil Engineering, vol. 19, no. 3, pp. 347-365, 2015.

[4] Y.-F. Zhang, J.-H. Zhao, and D.-F. Zhang, "Force transference mechanism and bearing capacity of connection between composite CFST column and steel beam," Journal of Chang'an University, vol. 35 , no. 5, pp. 82-88, 2015, in Chinese.

[5] D.-F. Zhang, J.-H. Zhao, C.-G. Zhang et al., "Research on cumulative energy dissipation for connections of concretefilled double skin steel tubular columns with steel beams," World Earthquake Engineering, vol. 33, no. 1, pp. 59-68, 2017, in Chinese.

[6] Y.-F. Huang, "Seismic behavior of concrete filled steel tubular built-up columns," Doctoral dissertation, University of Trento University, Venice, Italy, 2015.

[7] Y.-J. Kim, S.-H. Oh, and T.-S. Moon, "Seismic behavior and retrofit of steel moment connections considering slab effects," Engineering Structure, vol. 26, no. 13, pp. 1993-2005, 2004.

[8] C.-T. Cheng, C.-F. Chan, and L.-L. Chung, "Seismic behavior of steel beams and CFT column moment-resisting connections with floor slabs," Journal of Constructional Steel Research, vol. 63, no. 11, pp. 1479-1493, 2007.
[9] F.-Y. Liao, L.-H. Han, and Z. Tao, "Behavior of composite joints with concrete encased CFST columns under cyclic loading: experiments," Engineering Structure, vol. 59, pp. 745-764, 2014.

[10] L.-H. Han and W. Li, "Seismic performance of CFST column to steel beam joint with RC slab: experiments," Journal of Constructional Steel Research, vol. 66, no. 11, pp. 1374-1386, 2010.

[11] GB/T 228.1-2010, Metallic Materials-Tensile Testing-Part I: Method of Test at Room Temperature, China Standard Press, Beijing, China, 2010, in Chinese.

[12] JGJ/T 101-2015, Specification for Seismic Test of Buildings, China Architecture and Building Press, Beijing, China, 2015, in Chinese.

[13] J.-R. Tang, Seismic Resistance of Joints in Reinforced Concrete Frames, Southeast University Press, Nanjing, China, 1989, in Chinese.

[14] JGJ 138-2016, Code for Design of Composite Structures, China Architecture and Building Press, Beijing, China, 2016, in Chinese.

[15] GB50011-2010, Code for Seismic Design of Buildings, China Architecture and Building Press, Beijing, China, 2010, in Chinese.

[16] CECS 159, Technical Specification for Structures with Concrete-Filled Rectangular Steel Tube Members, China Planning Press, Beijing, China, 2004, in Chinese.

[17] L. Zeng, Y.-F. Xiao, Y.-G. Chen et al., "Cyclical behavior of concrete-encased composite frame joints with high strength concrete," Advances in Materials Science and Engineering, vol. 2015, Article ID 873162, 13 pages, 2015. 


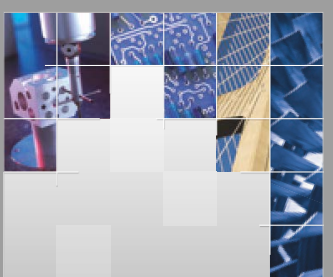

\section{Enfincering}
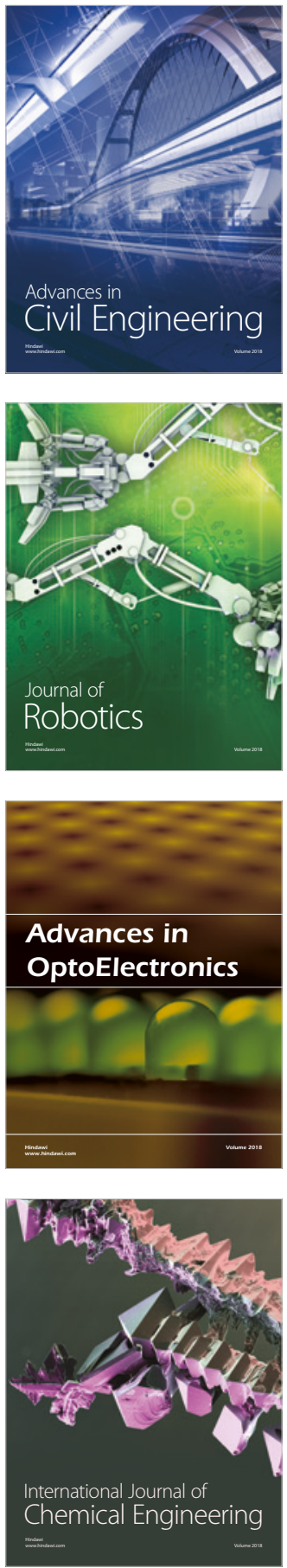

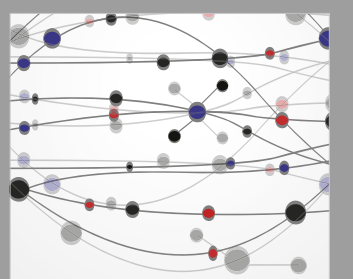

\section{Rotating \\ Machinery}

The Scientific World Journal

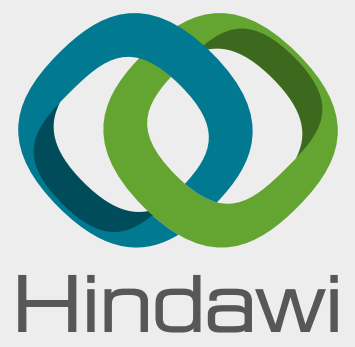

Submit your manuscripts at

www.hindawi.com
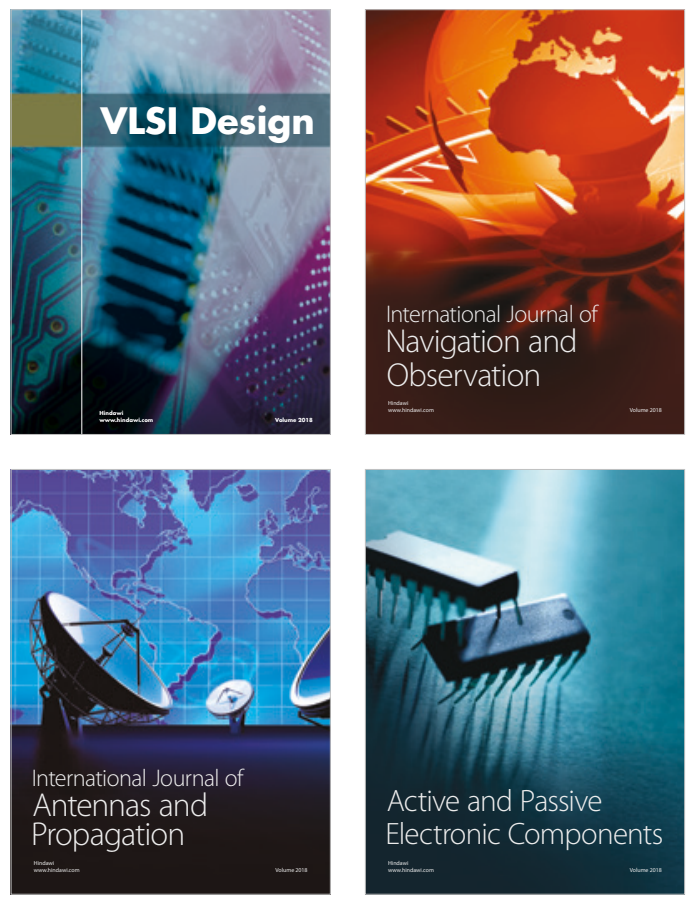
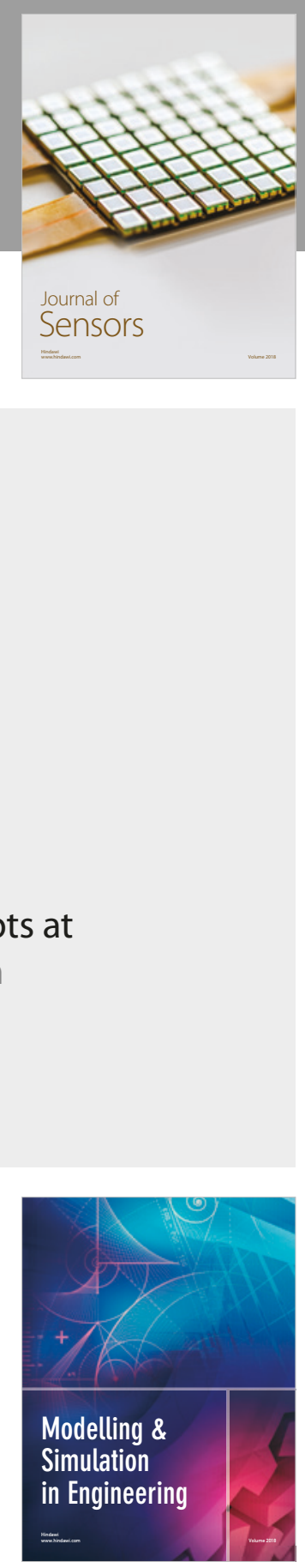

\section{Advances \\ Multimedia}
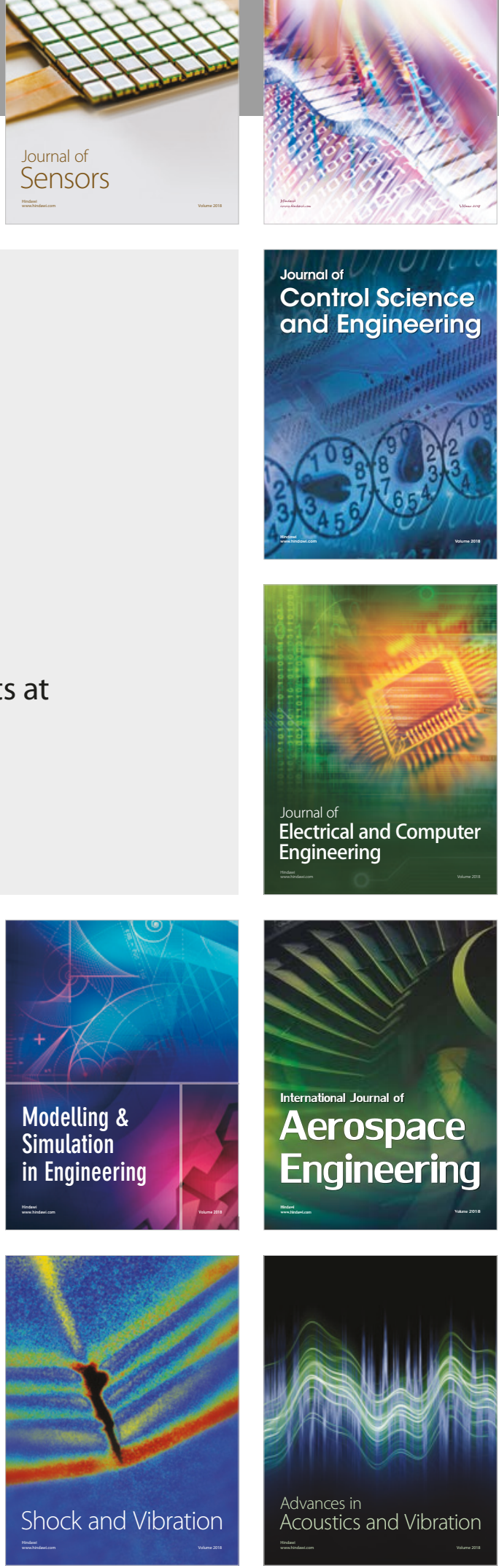